\title{
Mathematical modeling and performance analysis of a solar air collector with slit-perforated corrugated plate
}

\author{
Huan Zhanga ${ }^{\mathrm{a}}$ Xintong Ma ${ }^{\mathrm{a}}$, Shijun You ${ }^{\mathrm{a}}$, Yaran Wang ${ }^{\mathrm{a}}$, Xuejing Zhenga ${ }^{\mathrm{a}}$, Tianzhen Ye ${ }^{\mathrm{a}}$, \\ Wandong Zheng ${ }^{\mathrm{a}}$, Shen Wei ${ }^{\mathrm{b}}$ \\ ${ }^{a}$ School of Environmental Science and Engineering, Tianjin University, Haihe Education Area, \\ Jinnan District, Tianjin 300350, PR China \\ ${ }^{\mathrm{b}}$ The Bartlett School of Construction and Project Management, University College London \\ (UCL), 1-19 Torrington Place, London WC1E 7HB, United Kingdom \\ * Corresponding author. Tel.: +86-22-27400832; fax: +86-22-27892626. E-mail addresses: \\ yaran_wang@tju.edu.cn
}

\section{Highlights:}

A solar air collector with slit-perforated corrugated plate is studied.

Its thermal and flow characteristics are analyzed by mathematic model.

Optimized values of structure and operating parameters are put forward.

The collector shows better thermal performance and lower resistance.

\begin{abstract}
In this paper, a solar air collector with slit-perforated corrugated plate is put forward, which is a combination of transpired solar air collector and corrugated packing solar air collector. The slitperforated corrugated plate can enlarge the heat collection area and reinforce the jet impingement largely. The mathematical model is developed to predict thermal performance of the collector. Simulation results of temperature distribution in the collector are verified by the experimental data with the average bias of $4.8 \%$. The local resistance coefficient of the collector is obtained though experimental results. The effects of key parameters on thermal efficiency are analyzed. It can be found that the height of absorber plate has the largest effect on thermal performance among structure parameters. And when air velocity in the collector increases to $1.14 \mathrm{~m} / \mathrm{s}$, effective efficiency can reach the peak, $67.83 \%$. Compared with other transpired solar air collectors, the present solar air
\end{abstract}


collector has better thermal performance and lower resistance. Case study shows that the application of the present solar air collector can produce $820.7 \mathrm{MJ}$ in the heating season, which can save 43.1 $\mathrm{kg}$ standard coal and reduce $102.1 \mathrm{~kg}$ carbon dioxide emission. Hence, there is application potential for space heating in the cold region.

Keywords: Glazed transpired solar air collector; Slit-perforated corrugated plate; Local resistance coefficient; Performance analysis

\section{Introduction}

Due to the higher demand of energy and severe environmental issues in the world, solar energy is receiving more attention. Now in the solar market, solar thermal technology accounts for nearly 66\% (Li et al., 2017). Among solar thermal usages, solar air collectors (SAC) are widely used all over the world, and mostly applied in drying agricultural food (Essalhi et al., 2017) and space heating (Gao et al., 2014).However, thermal efficiency of conventional SACs is low, which is due to the low heat convention coefficient between collector air and absorber plate. Hence, optimization of the absorber plate is adopted to achieve high thermal efficiency.

Thermal efficiency of solar air collector can be improved by using turbulators on the absorber plate, such as ribs, fins and different shapes of turbulators (Alam et al., 2014). Singh et al. (2015) investigated the performance of solar air collectors with V-down rib and it is proved to have better thermal performance compared with similar collectors. Thermal performance of fined flat solar air collector was investigated by Karim et al. (2006). Compared with flat and v-corrugated flat solar air collector, fined plate solar air collector has better thermal performance. Furthermore, the pin-fin absorber plate packed with paraffin was investigated by Kumar et al. (2016), and the results confirmed that it can enhance the thermodynamic performance. Based on pin-fin absorber plate, circular and triangular tube packed bed absorber plate packed with paraffin wax were also put forward, and it was proved that triangular tube packed bed absorber plate has the superior thermal performance. (Kumar et al., 2017) Rajaseenivasan et al. (2015) investigated the solar air collector with circle and V-type turbulators attached on the absorber plate, and it shows better thermal performance than other conventional collectors. In addition to these tabulators, jet impingement is also an effective method to enhance convective heat transfer. The application of transpired absorber plate can effectively improve thermal performance of solar air collector. And it was proved that the thermal efficiency of transpired collector is higher than that of other types of collectors (Kumar et al., 2009).

Transpired collectors are classified into two types based on the glazing, respectively unglazed transpired solar collector (UTC) and glazed transpired solar collector (GTC). In the early 1990s, UTC was introduced for pre-heating ventilation air and space heating. (Leon, 2007) Many investigators began to study the performance of UTC. Kutscher (1994) investigated the heat transfer of UTC and put forward the correlation of heat exchange effectiveness and pressure drop. On the basis of Kutscher's data, Decker et al. (2001) expanded the experimental data and made a new model with high accuracy to predict thermal performance of UTC. Besides, Leon and Kumar (2007) and Golneshan et al. (2014) also made further study on thermal model of UTC and conducted the optimization of UTC. However, due to no glazing, the radiative and convective heat loss from absorber plate and environment is large. Gao et al. (2007) has investigated the performance of GTC 
and proved that GTC had better thermal performance compared with UTC. Based on the method of porous plate, a GTC with slit-like perforation was put forward and investigated by Li et al. (2014). And Li et al. (2016) continued to conclude the local resistance coefficient correlation of absorber plate with slit-like perforation and it was proved to be smaller at constant $\sigma$ and $R e_{h}$ is smaller compared with circular holes reported by Kutscher (1994). Due to the enlargement of the heat collection area, corrugated plate is also a good choice to enhance thermal performance. El-Sebaii et al. (2011) have proved that the v-corrugated plate solar air heater is $11-14 \%$ more efficient compared to the flat plate solar air heater. A GTC with perforating corrugated plate was came up by Zheng et al. (2016), and the results showed that it thermal performance was better than other transpired SACs.

Therefore, based on previous studies, the method of combining slit perforation and corrugated plate is put forward. Slit-perforated corrugated plate can enlarge the heat collection area and reinforce the jet impingement largely. The application of glazing cover can reduce the heat loss from absorber plate effectively. This paper aims to investigate the performance of glazed transpired solar collector with slit-perforated corrugated plate. The thermal model is established to predict the thermal characteristics of this SAC and validated by experimental results. And the local resistance coefficient is concluded though experimental data. The effect of key parameters on the thermal efficiency are investigated. The optimized parameters of structure and operation are obtained to provide better advice on the design of this collector for different applications. Case study is made to analyze the potential of the present SAC in the heating season.

\section{Mathematical model}

\subsection{Model simplification}

The configuration of the collector is illustrated in Fig.1, including cover, absorber plate, insulation backboard and shell. The cover is made of polyurethane due to the character of high transmissivity and low density. The UV protection is painting on the outer cover to prevent oxidation stain. The absorber plate is made of corrugated plate with slit perforation with black coating. The backboard is made of extruded polystyrene board (XPS) due to its good adiabatic performance. And the shell are made of steel plain sheet, which can enhance the strength of collector Air gets through the slit perforation and flows along the absorber plate to get the heat from sun's radiation. 

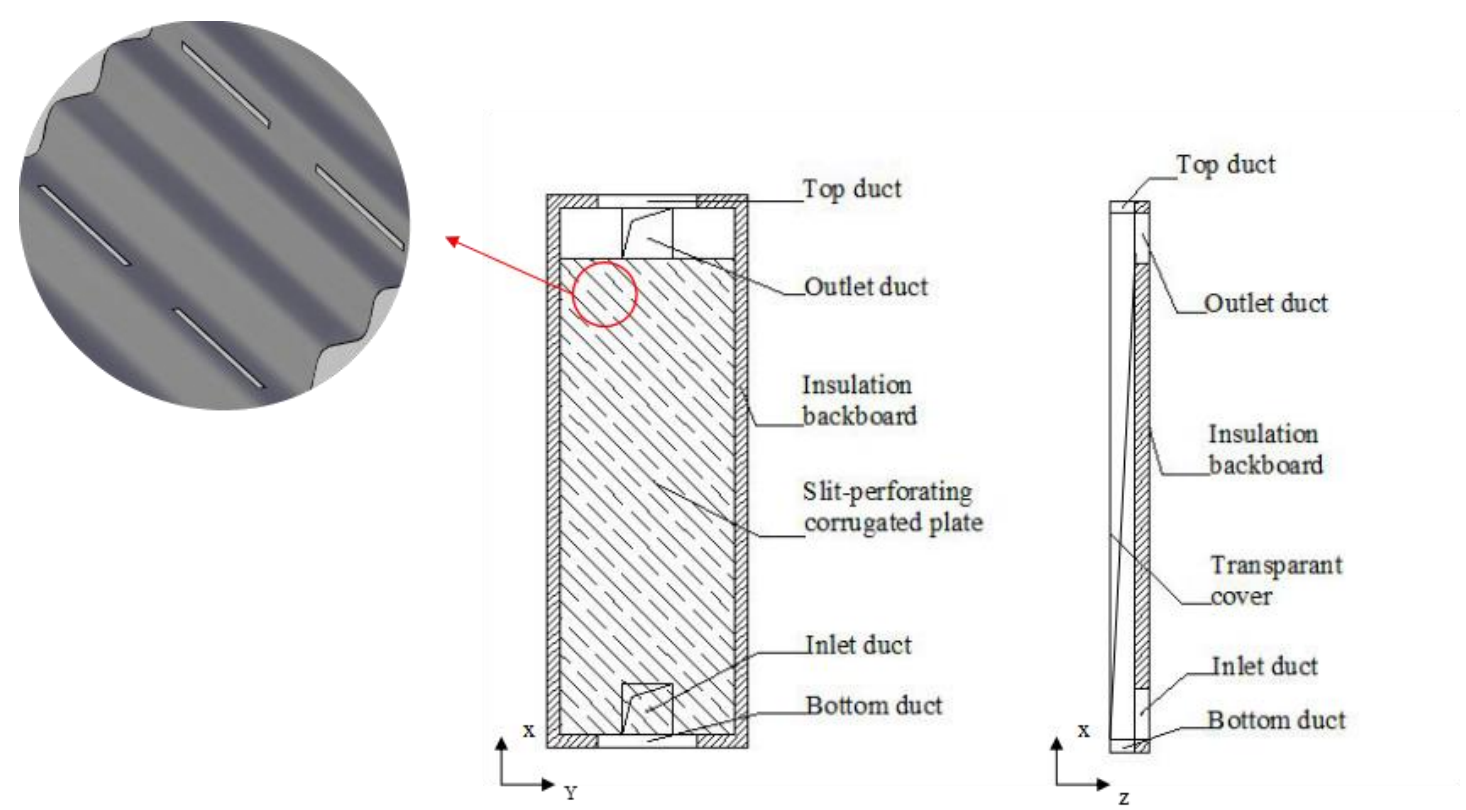

Fig. 1 Schematic diagram of GTC.

The mathematical model of the collector is made to describe the heat exchange process in a steady state. In addition, assumptions are made as follows: (Gao et al., 2014; Li et al., 2014)

(a) There is no air leakage in the collector.

(b) Airflow through the slit-perforated plate is assumed homogeneous.

(c) Heat loss of insulation backboard and sides is ignored.

(d) Thermal properties of cover, absorber plate and backboard are all kept constant.

(e) Heat transfer of all components is one dimensional, along $\mathrm{X}$ direction.

(f) The absorber plate is diffuse and gray for all absorbed and emitted radiation.

\subsection{Heat balance equations}

For transpired collectors, heat transfer relationship and processing method are usually similar (Li et al., 2016). Heat balance equations are obtained from the heat exchange relations of collector components, respectively cover, the air between cover and absorber plate (named Fluid 1), absorber plate, the air between absorber plate and backboard (named Fluid 2), backboard, shown in Fig. 2. The heat exchange relationships are as follows:

(a) Solar radiation absorbed by Cover $\left(S_{c}\right)$ and absorber plate $\left(S_{p}\right)$.

(b) Radiation heat transfer between cover and ambient environment $\left(q_{r c \sim a}\right)$, between cover and absorber plate $\left(q_{r \cdot c \sim p}\right)$, between backboard and absorber plate $\left(q_{r . b \sim p}\right)$.

(c) Convective heat transfer between cover and ambient environment $\left(q_{c v . c \sim a}\right)$, between cover and Fluid $1\left(q_{c v, c \sim f l}\right)$, between absorber plate and Fluid $1\left(q_{c v . p \sim f l}\right)$, between absorber plate and Fluid $2\left(q_{c v . p \sim f 2}\right)$, between backboard and Fluid $2\left(q_{c v . b \sim f 2}\right)$.

(d) Conductive heat transfer of cover $\left(q_{c d . c}\right)$, Fluid $1\left(q_{c d . f l}\right)$, absorber plate $\left(q_{c d . p}\right)$, Fluid $2\left(q_{c d . f 2}\right)$ and backboard $\left(q_{c d . b}\right)$.

(e) Convective heat transfer of Fluid $1\left(q_{c v . f l}\right)$ and Fluid $2\left(q_{c v . f 2}\right)$ 


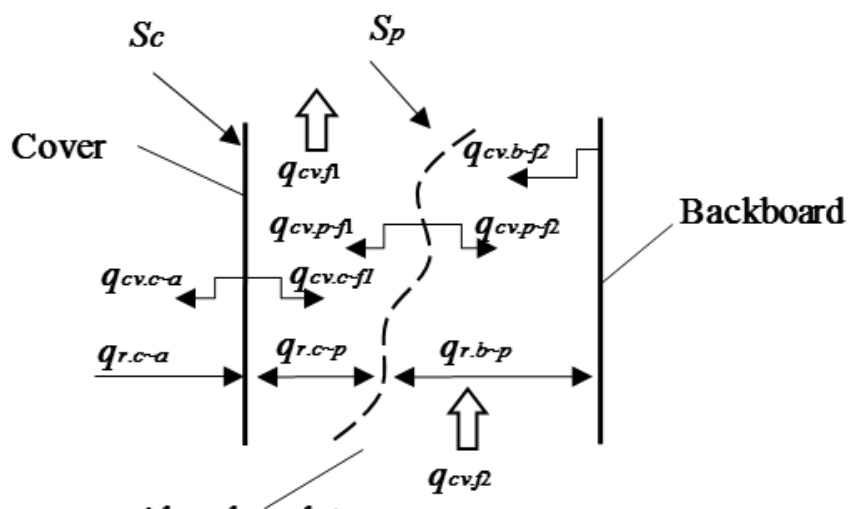

Absorber plate

Fig. 2 Heat exchange relations for heat balance.

Heat balance equations are as follows:

Cover:

$$
S_{c}+q_{c d . c}-q_{c v . c \sim a}-q_{c v . c \sim f l}-q_{r . c \sim p}-q_{r . c \sim a}=0
$$

Fluid 1:

$$
q_{c d . f 1}+q_{c v . c \sim f 1}+q_{c v . p \sim f 1}-q_{c v . f 1}=0
$$

Absorber plate

$$
S_{p}+q_{c d . p}-q_{c v . p \sim f 2}-q_{c v . p \sim f 1}+q_{r . b \sim p}+q_{r . c \sim p}=0
$$

Fluid 2:

$$
q_{c d . f 2}+q_{c v . b \sim f 2}+q_{c v . p \sim f 2}-q_{c v . f 2}=0
$$

Backboard:

$$
q_{c d . b}-q_{c v . b \sim f 2}-q_{r . b \sim p}=0
$$

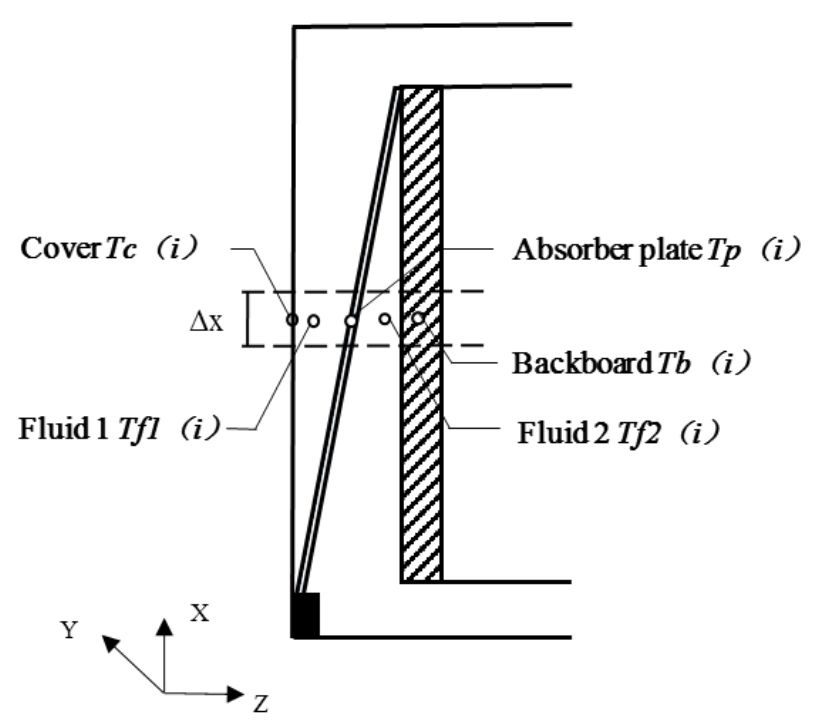

Fig. 3 Node i.

In order to establish these equations, finite-difference method is used in $n$ nodes which are 
divided in five components along $\mathrm{X}$ direction. (Fig. 3) Heat balance equations of $i$ node are as follows.

Cover:

$$
\begin{aligned}
& \alpha_{c} I_{c}+\lambda_{c} \delta_{c} \frac{T_{c}(i+1)+T_{c}(i-1)-2 T_{c}(i)}{\Delta x^{2}}-h_{c v . c \sim a}\left(T_{c}(i)-T_{a}\right)-h_{c v . c \sim f l}\left(T_{c}(i)-T_{f l}(i)\right) \\
& -h_{r . c \sim p}\left(T_{c}(i)-T_{p}(i)\right)-h_{r . c \sim a}\left(T_{c}(i)-\sqrt[4]{0.5 \varepsilon_{s k y}+0.5} T_{a}\right)=0
\end{aligned}
$$

Fluid 1:

$$
\begin{aligned}
& \lambda_{a} d_{f l} \frac{T_{f l}(i+1)+T_{f l}(i-1)-2 T_{f l}(i)}{\Delta x^{2}}+h_{c v, c \sim f l}\left(T_{c}(i)-T_{f l}(i)\right) \\
& +h_{c v . p \sim f l}\left(T_{p}(i)-T_{f l}(i)\right)(1-p) / \sin \theta+h_{c v . s l i t}\left(T_{p}(i)-T_{f 2}(i)\right) \frac{\delta_{p} l}{W \Delta x} \\
& -\frac{1}{3600} \frac{\rho C}{W \Delta x}\left[Q_{f l}(i+1) \frac{T_{f l}(i+1)+T_{f l}(i)}{2}-Q_{f l}(i) \frac{T_{f l}(i-1)+T_{f 1}(i)}{2}-\Delta Q T_{f 2}(i)\right]=0
\end{aligned}
$$

Absorber board:

$$
\begin{aligned}
& \tau_{c} \alpha_{p} I_{c}+\lambda_{p} \delta_{p} \frac{T_{p}(i+1)+T_{p}(i-1)-2 T_{p}(i)}{\Delta x^{2} / \sin \theta} \\
& -h_{c v . p \sim f 1}\left(T_{p}(i)-T_{f 1}(i)\right)(1-p) / \sin \theta-h_{c v . s i t}\left(T_{p}(i)-T_{f 2}(i)\right) \frac{\delta_{p} l}{W \Delta x} \\
& -h_{c v . p \sim f 2}\left(T_{p}(i)-T_{f 2}(i)\right)(1-p) / \sin \theta+h_{r . b \sim p}\left(T_{b}(i)-T_{p}(i)\right)+h_{r . c \sim p}\left(T_{c}(i)-T_{p}(i)\right)=0
\end{aligned}
$$

Fluid 2:

$$
\begin{aligned}
& \lambda_{a} d_{f 2} \frac{T_{f 2}(i+1)+T_{f 2}(i-1)-2 T_{f 2}(i)}{\Delta x^{2}} \\
& +h_{c v . b \sim f 2}\left(T_{b}(i)-T_{f 2}(i)\right)+h_{c v . p \sim f 2}\left(T_{p}(i)-T_{f 2}(i)\right)(1-p) / \sin \theta \\
& -\frac{1}{3600} \frac{\rho C}{W \Delta x}\left[Q_{f 2}(i+1) \frac{T_{f 2}(i+1)+T_{f 2}(i)}{2}-Q_{f 2}(i) \frac{T_{f 2}(i-1)+T_{f 2}(i)}{2}-\Delta Q T_{f 2}(i)\right]=0
\end{aligned}
$$

Backboard:

$$
\lambda_{b} \delta_{b} \frac{T_{b}(i+1)+T_{b}(i-1)-2 T_{b}(i)}{\Delta x^{2}}-h_{c v \cdot b \sim f 2}\left(T_{b}(i)-T_{f 2}(i)\right)-h_{r . b \sim p}\left(T_{b}(i)-T_{p}(i)\right)=0
$$

The boundary condition is as follow:

At collector inlet: $T_{f 2}(0)=T_{\text {in }}, Q_{f 1}(0)=0, Q_{f 2}(0)=Q$;

At collector outlet: $T_{f 1}(n)=T_{\text {out }}, Q_{f 1}(n)=Q, Q_{f 2}(n)=0$.

In addition, radiation heat transfer coefficients $h_{r . c \sim p}$ and $h_{r . b \sim p}$ are proposed by Karim et al. (2014). And radiation heat transfer coefficients $h_{r . c \sim a}$ is calculated by Kumar et al. (2009). Convection heat transfer coefficient $h_{c v . c \sim a}$ is recommended by McAdams (1954). For the flat plate, convection heat transfer cofficients $h_{c v . c \sim f 1}$ and $h_{c v . b \sim f 2}$ are calculated by Leon et al. (2007). For corrugated plate solar collectors, convection heat transfer coefficients $h_{c v \cdot p \sim f 1}$ and $h_{c v, p \sim f 2}$ are given by Piao (1992). For the laminar flow, convection heat transfer coefficient that suction from perforated 
plate is calculated as follows (Cho et al., 1997).

$$
\begin{gathered}
N u_{\text {slit }}=\frac{h_{c v . s i t} D}{\lambda_{a}}=3.66+0.1 \mathrm{Gz}_{\text {slit }} \\
\operatorname{Re}_{\text {slit }}=\frac{v_{\text {slit }} D}{v} \\
\mathrm{Gz}_{\text {slit }}=\operatorname{Re}_{\text {slit }} \operatorname{Pr} D / \delta_{p} \\
D=2 R
\end{gathered}
$$

Where the slit-perforation equivalent radius diameter $R$ can be confirmed by the method of Sun (1987), $R=0.971 b$.

These heat balance equations are solved by the software MATLAB. Fig. 4 is the calculation process, shown as follows:

(a) The values of structure and operation parameters are input.

(b) Attempt the values of $T_{c}, T_{p}$, and $T_{b}$.

(c) Solve equations with iteration method.

(d) If the differences between calculated and assumed value of $T_{c}, T_{p}$, and $T_{b}$ are all lower than $0.0001 \mathrm{~K}$, the calculation is end. Otherwise, go back to (c) and continue to calculate.

(e)The temperatures of each component (cover, Fluid 1, absorber plate, Fluid 2 and backboard) are output.

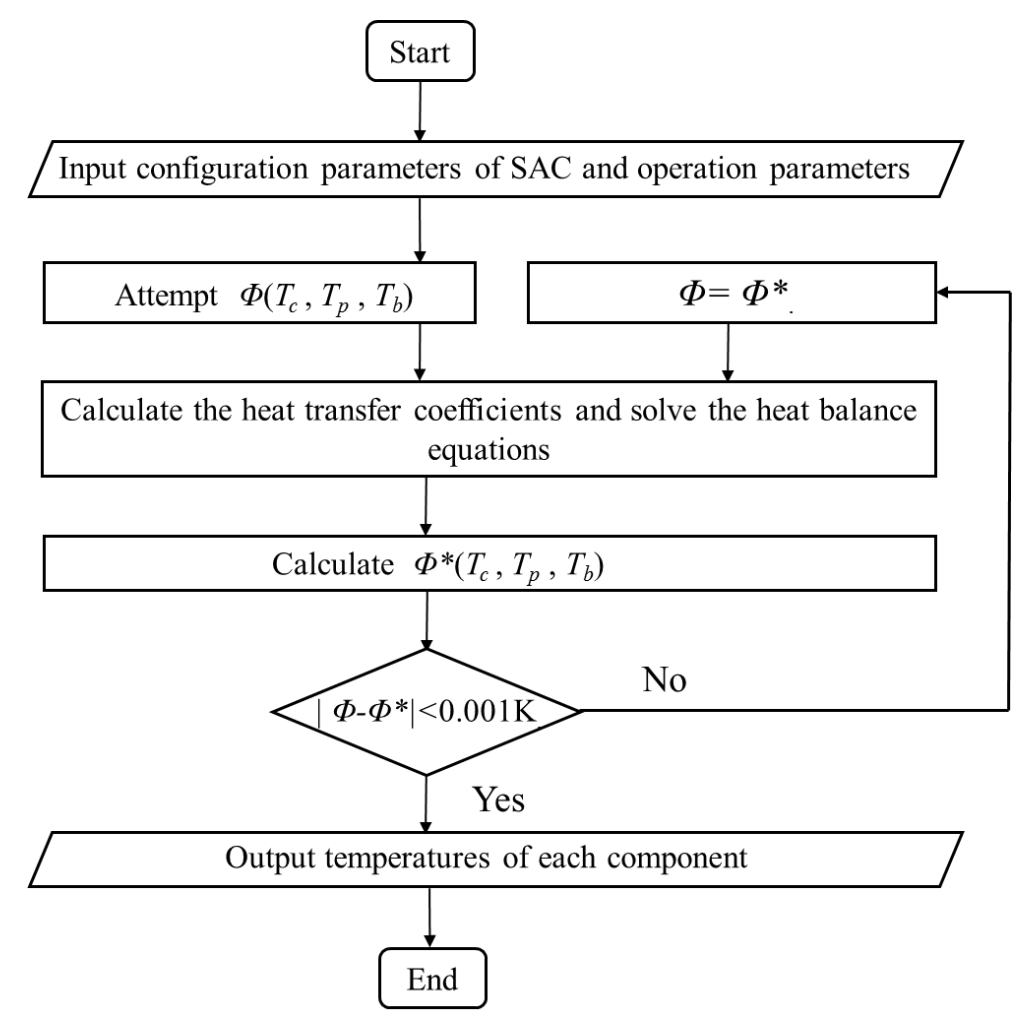

Fig. 4 Program calculation process. 


\section{Experimental study}

\subsection{Experimental apparatus}

The glazed transpired solar air collector with slit-perforated corrugated plate was conducted and tested in the city of Tianjin (117.10 E 39.10 N) in China. Experiments were performed in March. Fig. 5 is the photograph of the experimental set up. The dimensions of the collector is $0.7 \mathrm{~m}$ in width, $2.1 \mathrm{~m}$ in height and $0.16 \mathrm{~m}$ in thickness, shown in Fig.1 The aperture area $\left(A_{c}\right)$ is $0.7 \mathrm{~m}$ in width and $2.1 \mathrm{~m}$ in height. The size of absorber plate is $0.7 \mathrm{~m}$ in width and $1.9 \mathrm{~m}$ in height. The thickness is $0.0015 \mathrm{~m}$. And the material is the $45^{\circ}$ oblique slit-perforated corrugated plate with the specific surface area of $250 \mathrm{~m}^{2} / \mathrm{m}^{3}$. Its porosity is $1 \%$ with the equivalent diameters and pitch of slitperforation, $0.001 \mathrm{~m}$ and $0.1 \mathrm{~m}$ respectively. The absorber plate is black coated with the absorptivity 0.96. Besides, the transmissivity of cover was measured, 0.836 . The detailed physical parameters of collector components are in Tab.1. The $45^{\circ}$ oblique slit-perforated corrugated plate with the specific surface area of $250 \mathrm{~m}^{2} / \mathrm{m}^{3}$ was used to obtain heat. And the absorber plate's porosity is $1 \%$ with the absorptivity 0.96 . The equivalent diameter and pitch of slit-perforation is $0.001 \mathrm{~m}$ and 0.1 $\mathrm{m}$, respectively. The outlet and inlet ducts of the collector were used to connect the house with diameter of $200 \mathrm{~mm}$. A fan was set in the inlet duct of the collector. The maximum air flow rate of fan is $950 \mathrm{~m}^{3} / \mathrm{h}$. and air flow was adjusted by a damper.
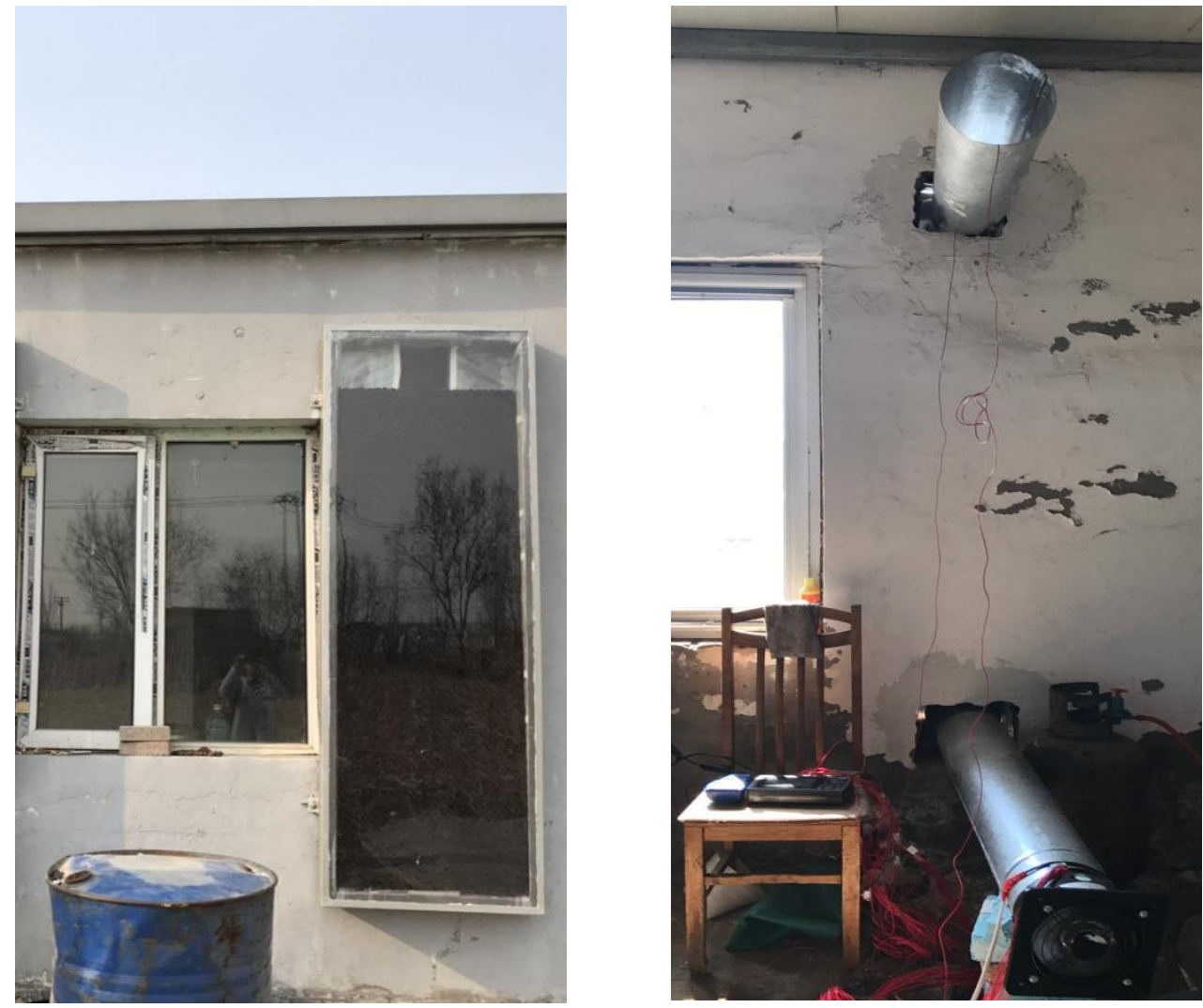

Fig. 5 Structure of experimental system. 
Tab. 1 Physical parameters of collector components.

\begin{tabular}{|c|c|c|c|c|}
\hline Component & Material & Parameter & Value & Units \\
\hline \multirow{3}{*}{ Cover } & \multirow{3}{*}{ Polyurethane } & Depth & 0.004 & $\mathrm{~m}$ \\
\hline & & Transmissivity & 0.836 & l \\
\hline & & Absorptivity & 0.1 & I \\
\hline \multirow{4}{*}{ Absorber plate } & \multirow{4}{*}{$\begin{array}{c}45^{\circ} \text { oblique } \\
\text { corrugated } \\
\text { stainless steel }\end{array}$} & Porosity & $1 \%$ & I \\
\hline & & $\begin{array}{c}\text { Pitch of } \\
\text { slit-perforation }\end{array}$ & 0.1 & $\mathrm{~m}$ \\
\hline & & $\begin{array}{l}\text { Equivanlent diameter } \\
\text { of slit-perforation }\end{array}$ & 0.001 & $\mathrm{~m}$ \\
\hline & & Absorptivity & 0.96 & I \\
\hline $\begin{array}{c}\text { Backboard and } \\
\text { side }\end{array}$ & $\begin{array}{c}\text { Extruded } \\
\text { polystyrene board }\end{array}$ & Depth & 0.05 & $\mathrm{~m}$ \\
\hline Shell & $\begin{array}{l}\text { Galvanized steel } \\
\text { plain sheet }\end{array}$ & Depth & 0.0012 & $\mathrm{~m}$ \\
\hline
\end{tabular}

The solar radiation intensity on the collector, outdoor wind velocity, ambient air temperature, inlet and outlet air temperatures of collector, temperatures of Fluid 1, Fluid 2 and absorber plate, inside air velocity and pressure drop through the collector were measured during the tests. The testing process is refer to the Standard (2011). The solar radiation intensity was measured on the top of the collector. The temperatures of Fluid 1, Fluid 2 and absorber plate were measured by 15 copper-constantan thermocouples. These thermocouples were divided into three groups and five for each group. The distribution of thermocouples was illustrated in Fig. 6. The ambient air temperature, collector inlet and outlet temperatures were also measured by thermocouples. All the thermocouples were checked by thermostatic waterbath and covered by tinfoil to eliminate the influence of solar radiation. Pressure drops were measured between inlet and outlet duct. Temperature readings were recorded by Fluke 2866A. The detailed instrument information is presented in Tab. 2 .

Air flow rate is obtained by multiplying duct area and measuring duct air velocity, which is calculated by Eq.(15).

$$
Q=\pi v_{d} d^{2} / 4
$$

Where $v_{d}$ is duct air velocity and $d$ is duct diameter

The uncertainty of air flow rate would be calculated according to Holman (2007) and Kumar et al. (2016). Through calculating Eq.(16), the uncertainty of air flow rate is $4.9 \%$.

$$
w_{Q}=\sqrt{\left(\frac{\partial Q}{\partial v_{d}} w_{v_{d}}\right)^{2}+\left(\frac{\partial Q}{\partial d} w_{d}\right)^{2}}
$$

Where $w_{v_{d}}$ is the uncertainty of duct air velocity and $w_{d}$ is the uncertainty of duct diameter. 


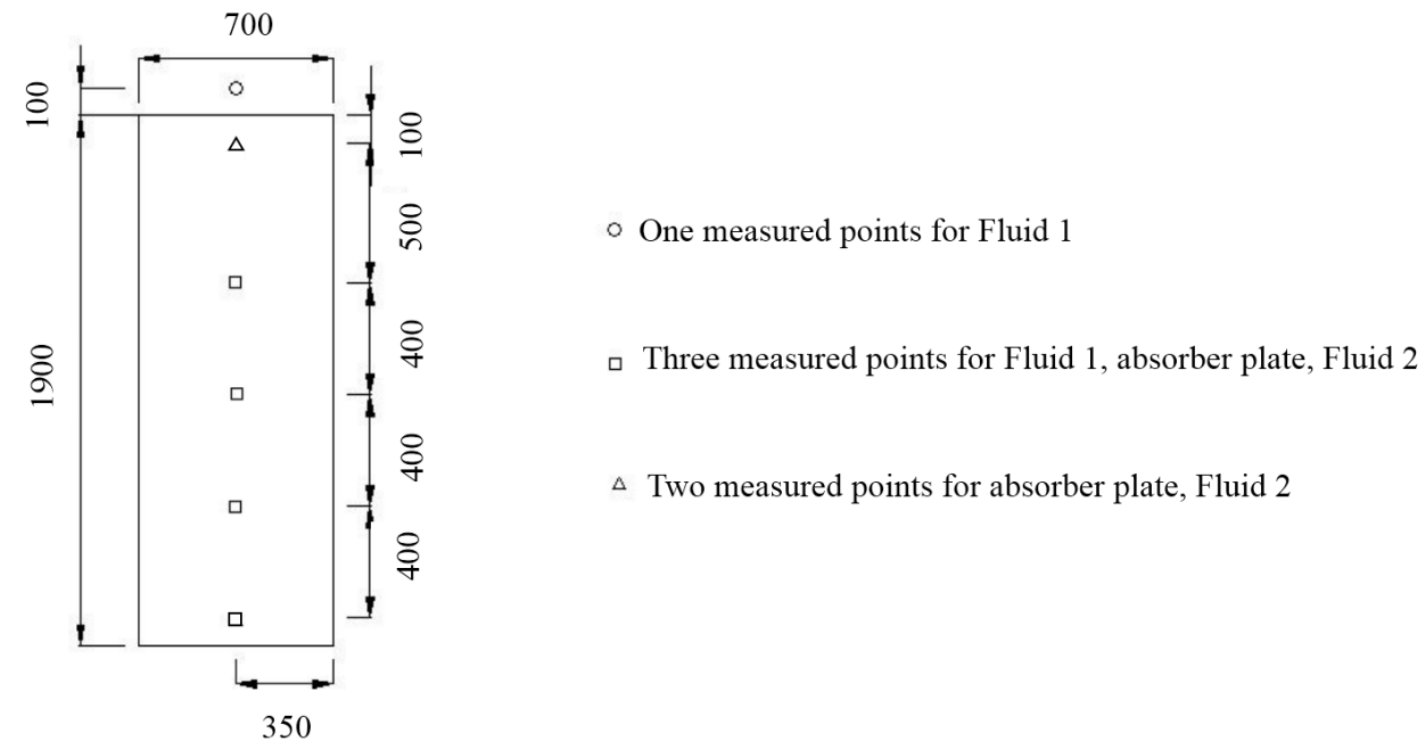

Fig. 6 The distribution of thermocouples in Fluid 1, Fluid 2 and absorber plate.

Tab. 2 Information of measured instruments.

\begin{tabular}{cccc}
\hline Measured item & Device & Full scale & accuracy \\
\hline Data acquisition instrument & Fluke 2686A & & \\
Air temperature & $\begin{array}{c}\text { Copper-constantan } \\
\text { thermocouple }\end{array}$ & $-200^{\circ} \mathrm{C}$ to $200^{\circ} \mathrm{C}$ & $\pm 0.5^{\circ} \mathrm{C}$ \\
solar radiation intensity & Radiometer TRT-2 & 0 to $2 \mathrm{~kW} / \mathrm{m}^{2}$ & $\pm 2 \%$ \\
Pressure drop & $\begin{array}{c}\text { Microelectronic pressure } \\
\text { gauge ADM-860C }\end{array}$ & 0 Pa to $150 \mathrm{~Pa}$ & $\pm(2 \% \pm 0.25 \mathrm{~Pa})$ \\
Duct air velocity & TSI VELOCICALC & 0 to $50 \mathrm{~m} / \mathrm{s}$ & $\pm 0.015 \mathrm{~m} / \mathrm{s}$ \\
Outdoor air velocity & 9565 & 0 to $40 \mathrm{~m} / \mathrm{s}$ & $\pm 0.02 \mathrm{~m} / \mathrm{s}$ \\
\hline
\end{tabular}

\subsection{Experimental verification of thermal model}

The experiment test was conducted in the follow condition: $I_{c}=793 \mathrm{~W} / \mathrm{m}^{2}, T_{a}=286.2 \mathrm{~K}$, $v_{a}=0.3 \mathrm{~m} / \mathrm{s}, T_{i n}=294.4 \mathrm{~K}, Q=149.3 \mathrm{~m}^{3} / \mathrm{h}$. Fig. 7 shows the comparison between the experimental and simulated temperatures of Fluid 1, absorber plate and Fluid 2. It is noticed that the simulated data is close to the experimental data with the average bias of $4.8 \%$. It is due to the existed experiment errors and the assumptions that simplified model put forward. In addition, the bias is larger in the collector inlet because of the nonuniform distribution of air in collector inlet. The biggest bias is $4.64 \mathrm{~K}$, which is acceptable.

In a word, the result implies that the thermal model can be considered correct and reliable for further studies. 


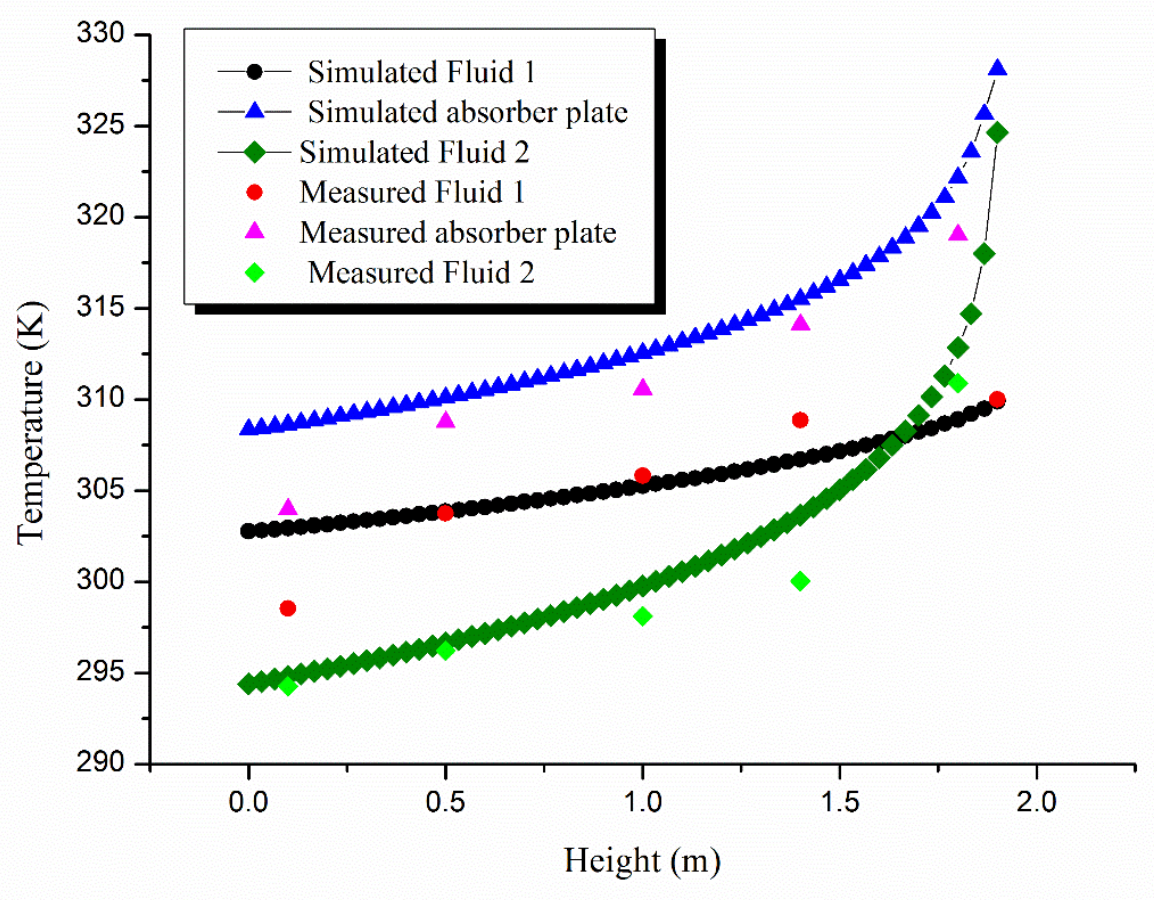

Fig. 7 Comparison between simulated and measured temperatures of Fluid 1, Fluid 2 and absorber plate.

\subsection{Pressure drop}

The pressure drop across the collector is made of local resistance loss $\left(\Delta P_{l}\right)$, and frictional resistance loss $\left(\Delta P_{f}\right)$, buoyancy pressure $\operatorname{drop}\left(\Delta P_{b}\right)$ and acceleration pressure drop ( $\left.\Delta P_{a c c}\right)$, and additional pressure drops caused by sudden changes of collector inlet and collector outlet. The collector height is small and $\Delta P_{b}$ and $\Delta P_{a c c}$ are ignored. The pressure drop can be calculated:

$$
\Delta p=\frac{1}{2} \rho \xi_{p} v_{\text {slit }}^{2}+f \rho \frac{4 H v_{f}}{2 D_{h}}+\xi_{\text {in }} \rho \frac{v_{f}^{2}}{2}+\xi_{\text {out }} \rho \frac{v_{f}^{2}}{2}
$$

Where $\xi_{\text {in, }} \xi_{\text {out }}, f$ are obtained from Kasperski et al. (2013).

The local drag coefficient is relevant with $p$ and $R_{s l i t}$ and proportional to $(1 / p-1)^{2}$. (Kutscher, 1994) For the absorber plate, the fitting curve of experimental data is shown in Fig. 8. Through testing pressure drops of the collector and calculating Eq.(15), the fitting correlation for the local drag coefficient is as follows:

$$
\xi_{p}=6.82\left(\frac{1}{p}-1\right)^{2} \operatorname{Re}_{s l i t}^{-0.51}
$$

The coefficient of determination $R^{2}$ is 0.96 . Compared with the flat plate with slit-like perforation ( $\mathrm{Li}$ et al., 2016), the local resistance coefficient of sit-perforating corrugated plate is smaller at same $p$ and $\operatorname{Re}_{\text {slit }}$. 


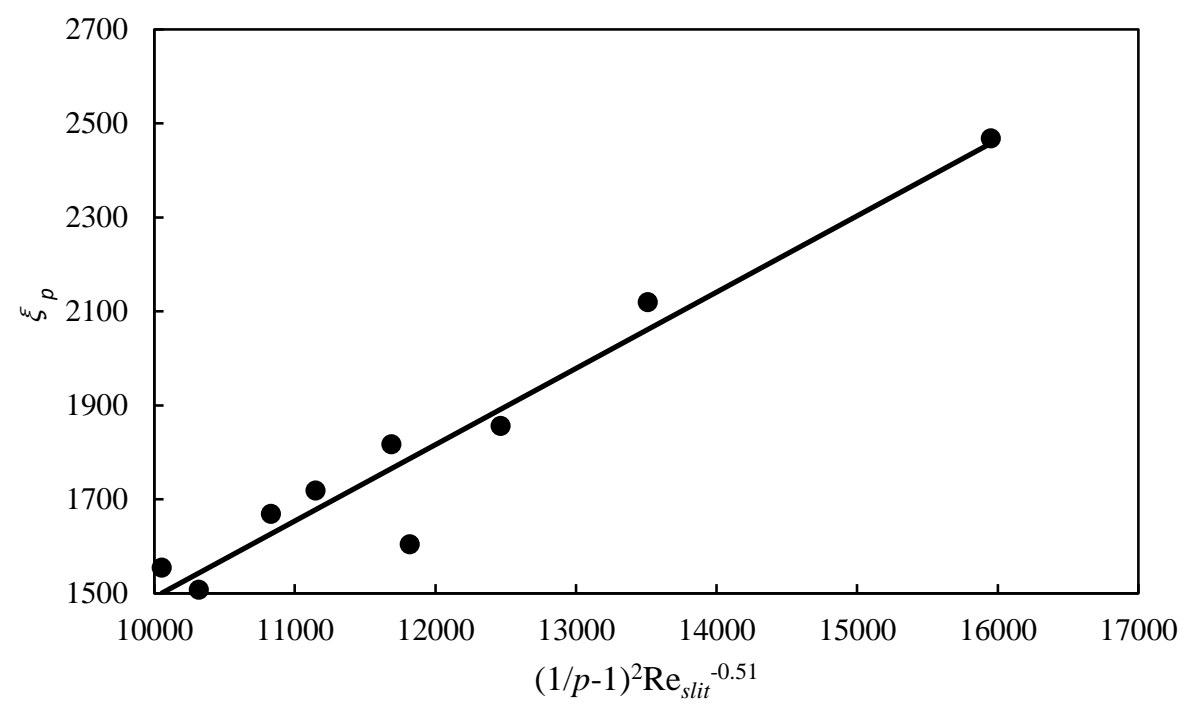

Fig. 8 The fitting curve of local resistance coefficient.

\section{Simulation results and discussion}

The analysis of structure design and operation conditions are conducted, and the simulation condition is as follows:

$W=0.7 \mathrm{~m}, H=1.9 \mathrm{~m}, D=0.001 \mathrm{~m}, P=0.1 \mathrm{~m}, \alpha_{c}=0.1, \tau_{c}=0.836, \alpha_{p}=0.96$,

$I_{c}=800 \mathrm{~W} / \mathrm{m}^{2}, T_{a}=286 \mathrm{~K}, T_{d p}=267 \mathrm{~K}, T_{\text {in }}=294 \mathrm{~K}, v_{\text {wind }}=0.30 \mathrm{~m} / \mathrm{s}, Q=144 \mathrm{~m}^{3} / \mathrm{h}$ 。

\subsection{Analysis of collector design}

\subsubsection{Height and width of absorber plate}

Thermal efficiency can show the heat transfer capacity of collector, the calculation method is as follows:

$$
\eta=\frac{q_{u}}{I_{c} A_{c}}=\frac{\rho C Q\left(t_{\text {out }}-t_{\text {in }}\right)}{I_{c} A_{c}}
$$

In Fig. 9, the heat collection increases with $H$ and $W$ due to the enlargement of absorber plate area. However, thermal efficiency increase to the peak, $67.4 \%$ at the $H$ of $3.0 \mathrm{~m}$, and then declines. It is due to the increase of the ratio between absorber plate area and light area. And the reason for a decline of thermal efficiency is increasing total heat amount and larger heat loss that caused by higher air temperature. Hence, the optimized $H$ can be obtained, $3.0 \mathrm{~m}$.

And in Fig. 9(b) it could be found that the value of thermal efficiency keep nearly constant at $66.7 \%$ when $W$ increases from $0.7 \mathrm{~m}$ to $1.6 \mathrm{~m}$. It is because heat transfer coefficient keep constant in the constant air velocity in the collector. The heat that unit absorber plate area collected would not change if the heat loss is not considered. It can be concluded that the increase of $W$ has no effect on thermal efficiency, but it can increase heat collection of collector. 


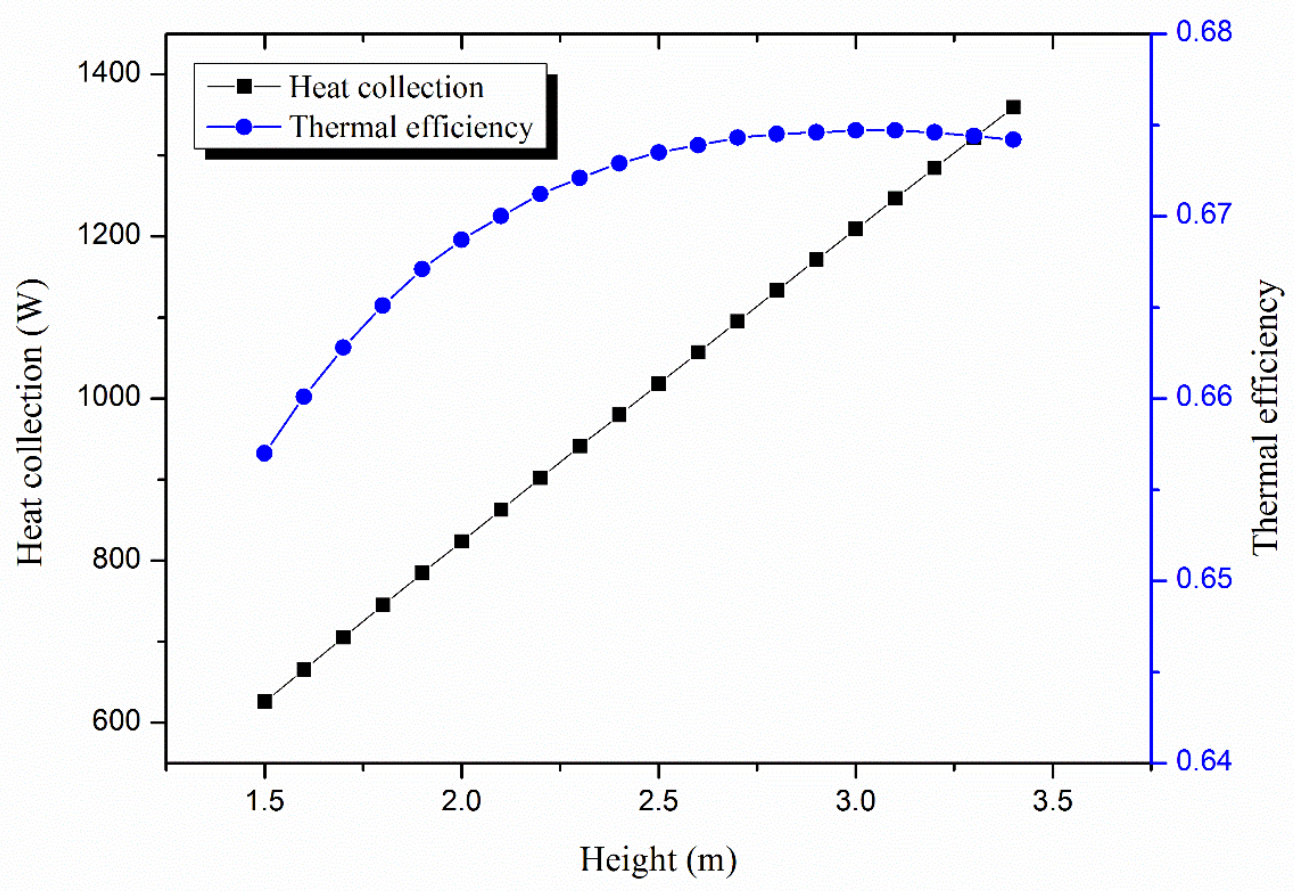

(a)

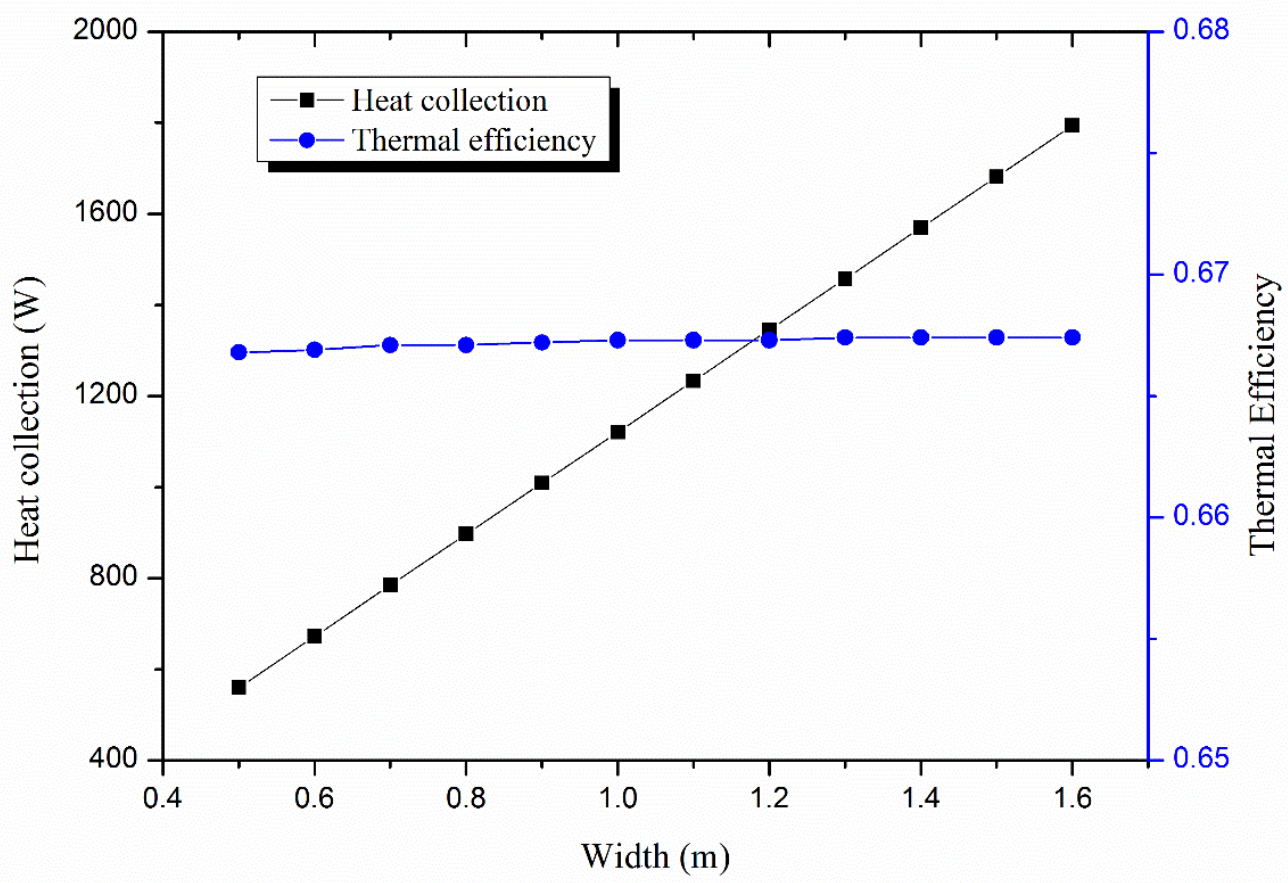

(b)

Fig. 9 Heat collection and thermal efficiency with absorber plate (a) height and (b) width.

\subsubsection{Perforation pitch and diameter}

When the slit-perforation diameter decreases from $0.003 \mathrm{~m}$ and to $0.001 \mathrm{~m}$, the slit-perforation 
area shrinks and slit velocity correspondingly increases. The combined effects contribute to the increase of $h_{\text {slit }}$, resulting in the improvement of heat collection. As the slit-perforation diameter is constant, heat collection increases for slit-perforation pitch from $0.08 \mathrm{~m}$ to $0.12 \mathrm{~m}$. It is because the slit-perforation number reduces and slit velocity correspondingly increases. It is positive for heatexchange, resulting in the increase of heat collection.

Fig. 10 presents the variation of heat collection and thermal efficiency with slit-perforation pith and diameter. It can be found that heat collection and thermal efficiency, increase with slitperforation pitch (an increase of $6.27 \mathrm{~W}$ and $0.6 \%$ for $D=0.001 \mathrm{~m}$ ) and decrease with slitperforation diameter (a drop of $3.52 \mathrm{~W}$ and $0.32 \%$ for $P=0.08 \mathrm{~m}$ ). The best combination of slitperforation diameter and pitch is $D=0.001 \mathrm{~m}$ and $P=0.12 \mathrm{~m}$ over the ranges of $D(0.001 \mathrm{~m} \sim 0.003 \mathrm{~m})$ and $P(0.08 \mathrm{~m} \sim 0.12 \mathrm{~m})$.

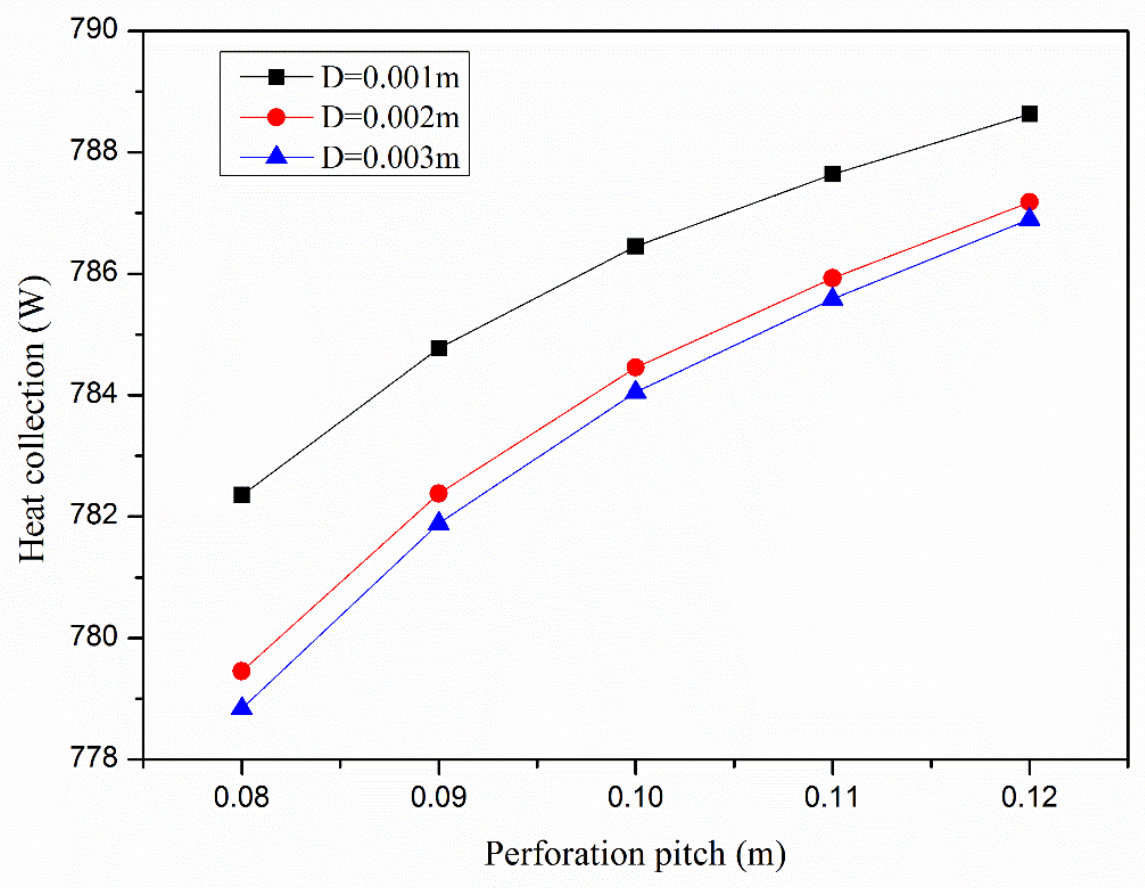

(a) 


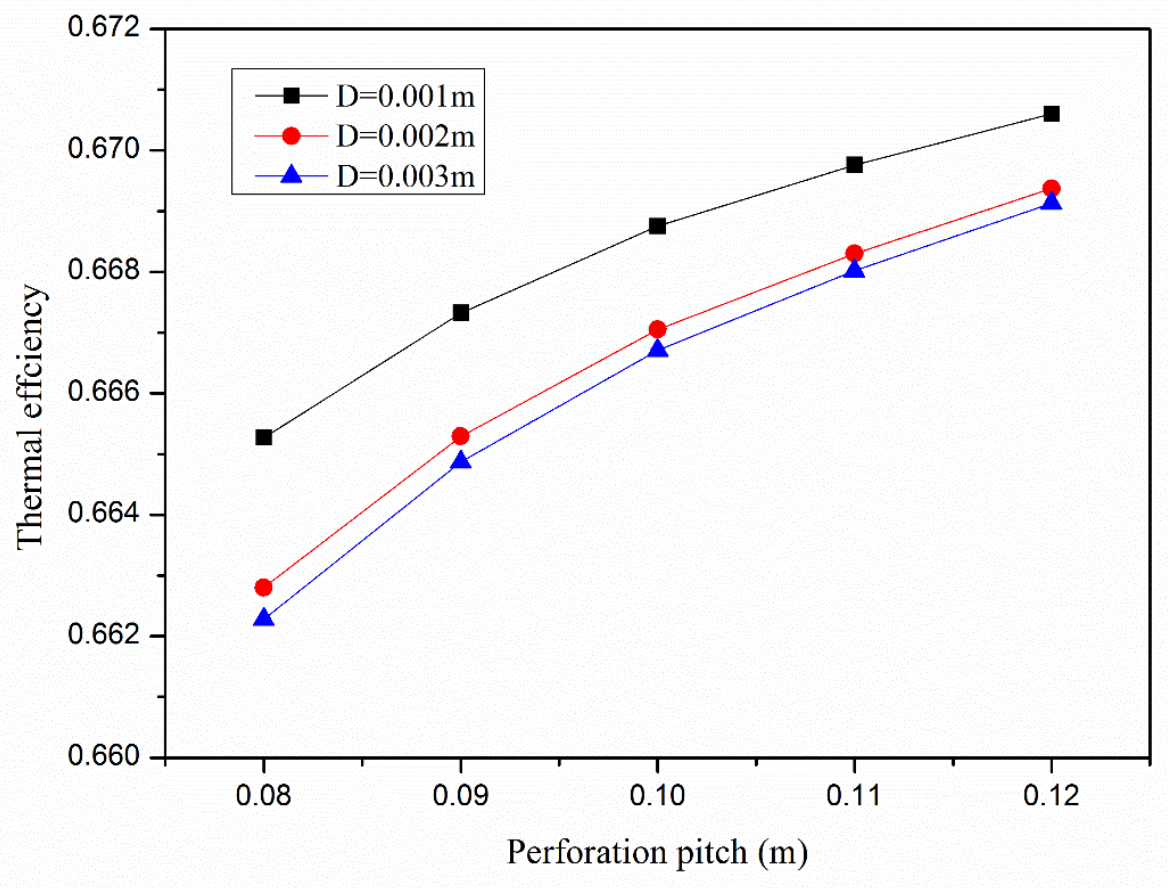

(b)

Fig. 10 (a) Temperature rise and (b) thermal efficiency with slit-perforation diameter and pitch.

\subsubsection{Main collector parameters effects on thermal efficiency}

The aim of this part is to use the Design of Experiments (DoE) method to estimate and compare the effect of collector parameters on thermal performance. Thermal efficiency is selected as the valuation index. According to the previous work, the relevant parameter ranges and levels of variation are summarized in the Tab. 3 .

Tab. 3 Parameters and levels

\begin{tabular}{cccccc}
\hline \multirow{2}{*}{ Symbol } & Factors & Unit & \multicolumn{3}{c}{ Level } \\
\cline { 4 - 6 } & & & Higher & Inter & Lower \\
\hline $\mathrm{A}$ & Height $(H)$ & $\mathrm{m}$ & 1.5 & 2.5 & 3.5 \\
$\mathrm{~B}$ & Width $(W)$ & $\mathrm{m}$ & 0.5 & 1 & 1.5 \\
$\mathrm{C}$ & Perforation & & & 0.008 & 0.01 \\
& Pitch $(P)$ & $\mathrm{m}$ & 0.008 & 0.003 \\
$\mathrm{D}$ & Perforation & & & & 0.002 \\
\hline
\end{tabular}

The plan matrix is made and the number of simulation cases are 16 . The data is analyzed by the method of contribution rate. (Su, 2005) The results are in Tab. 4. It can be found that the contribution rate of height of absorber plate is maximum, which shows that its effect on the thermal performance is the largest. The next one is the slit-perforation diameter. The width has nearly no effect on thermal performance. Therefore, it is important for designer to consider the height and perforation diameter of absorber plate over these ranges of collector parameters. 
Tab. 4 Effects of parameters.

\begin{tabular}{ccccc}
\hline Parameter & Height $(H)$ & Width $(W)$ & $\begin{array}{c}\text { Perforation } \\
\text { Pitch }(P)\end{array}$ & $\begin{array}{c}\text { Perforation } \\
\text { Diameter }(D)\end{array}$ \\
\hline Contribution rate & $88.2 \%$ & $0.1 \%$ & $1.5 \%$ & $10.2 \%$ \\
\hline
\end{tabular}

\subsection{Analysis of operation condition}

\subsubsection{Ambient and inlet air temperature}

Fig. 10 shows the decline of heat collection and thermal efficiency from $851 \mathrm{~W}, 77.3 \%$ to $784 \mathrm{~W}$, $66.7 \%$. It is due to the increase of inlet temperature, the temperature difference between collector air and absorber plate gets smaller, resulting in the weaken heat-exchange driving force. In addition, the increase of inlet temperature also contributes to the increase of $T_{b}$ and $T_{c}$, and the corresponding radiation heat coefficient $h_{r, c \sim p}$ and $h_{r, p \sim d}$ increases. Correspondingly heat loss coefficient $U$ increases from 1.53 to 1.68 in Fig. 11(b).

$$
U=U_{t}+U_{b}
$$

Top heat loss coefficient $U_{t}$ would be obtained by Zhang (2007); as the collector's backboard and sides have good adiabatic performance, $U_{b}$ can be ignored.

Fig. 11(a) shows the variation of thermal efficiency, increasing with ambient air temperature from $62.4 \%$ to $68.4 \%$. It is contributed to the smaller temperature difference between collector air and ambient air and the reduction of corresponding heat loss. For lower inlet temperature and higher ambient air temperature, the thermal efficiency of collector would be higher.

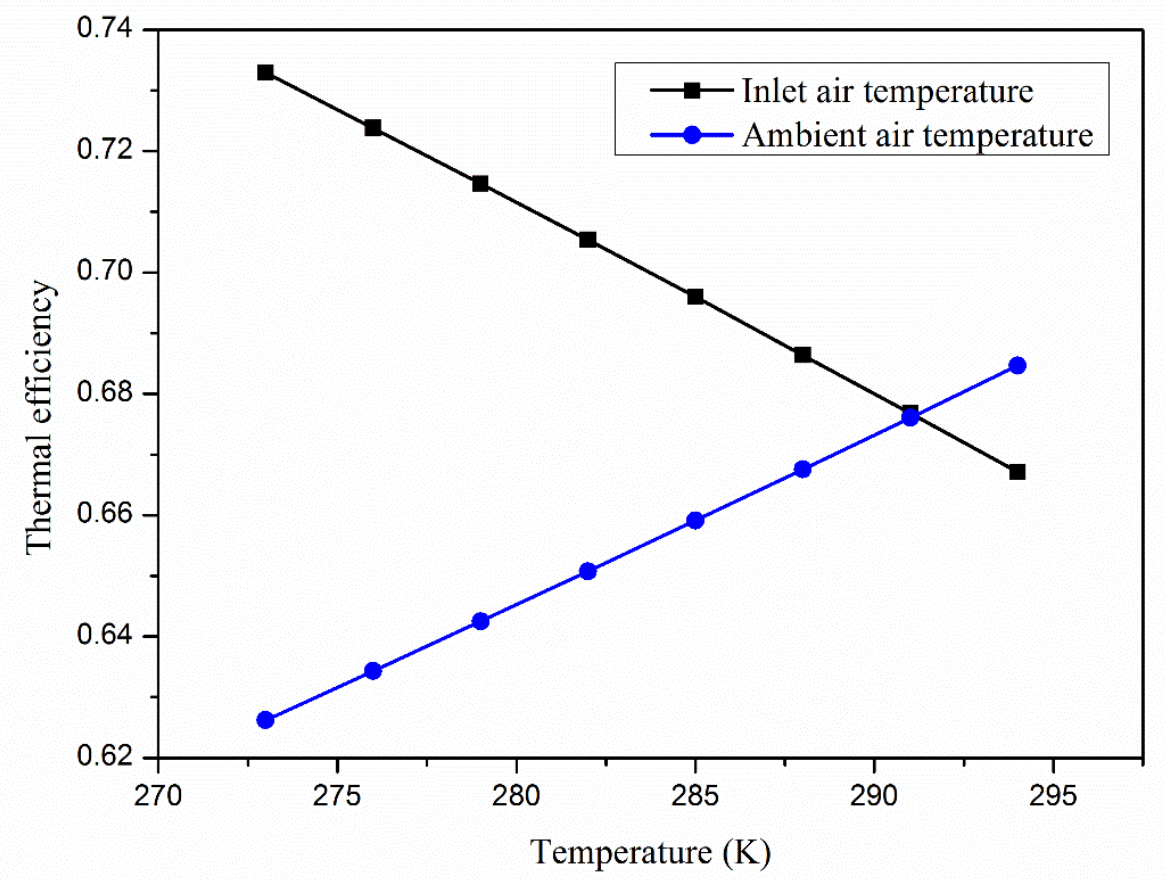

(a) 


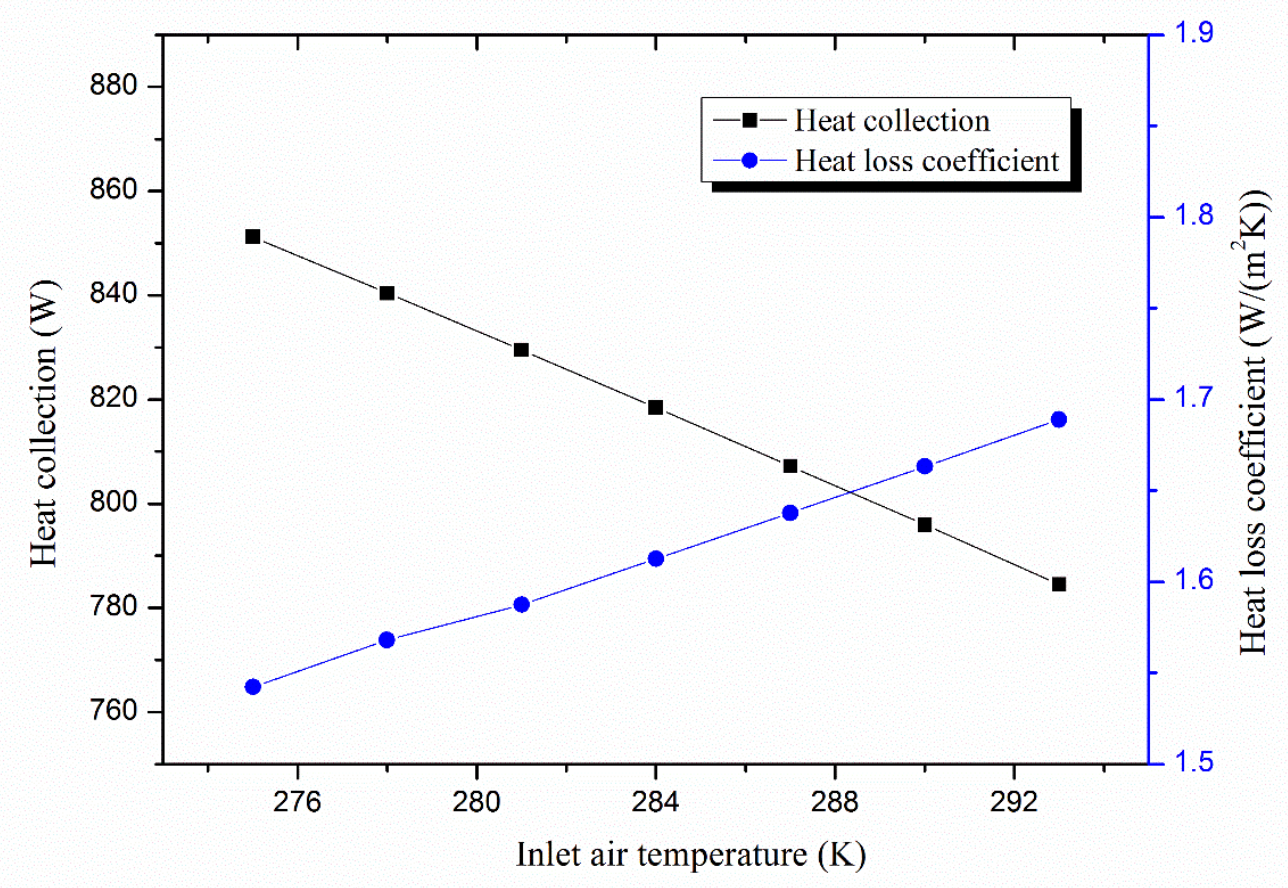

(b)

Fig. 11 (a) Thermal efficiency with inlet and ambient air temperature. (b)Heat collection and heat loss coefficient with inlet air temperature.

\subsubsection{Solar radiation intensity and outdoor wind velocity}

The increased solar radiation intensity causes the increase of heat collection, which results in the increase of thermal efficiency, as illustrated in Fig. 12(a). However, with the increase of solar radiation intensity, the temperature difference between collector air and absorber plate gets smaller, resulting in the slow growth rate of thermal efficiency.

Fig. 12(b) shows the effect of outdoor wind velocity on thermal efficiency. When the outdoor wind velocity increases from $0 \mathrm{~m} / \mathrm{s}$ to $10 \mathrm{~m} / \mathrm{s}$, thermal efficiency decreases from $67.2 \%$ to $63.3 \%$. The reason is that the heat transfer coefficient $h_{c, c \sim a}$ increases. Corresponding heat loss coefficient $U$ increases from 1.63 to 1.97 . The thermal efficiency of the collector is higher, under the condition of lower wind velocity, due to the reduced heat loss between cover and ambient environment. 


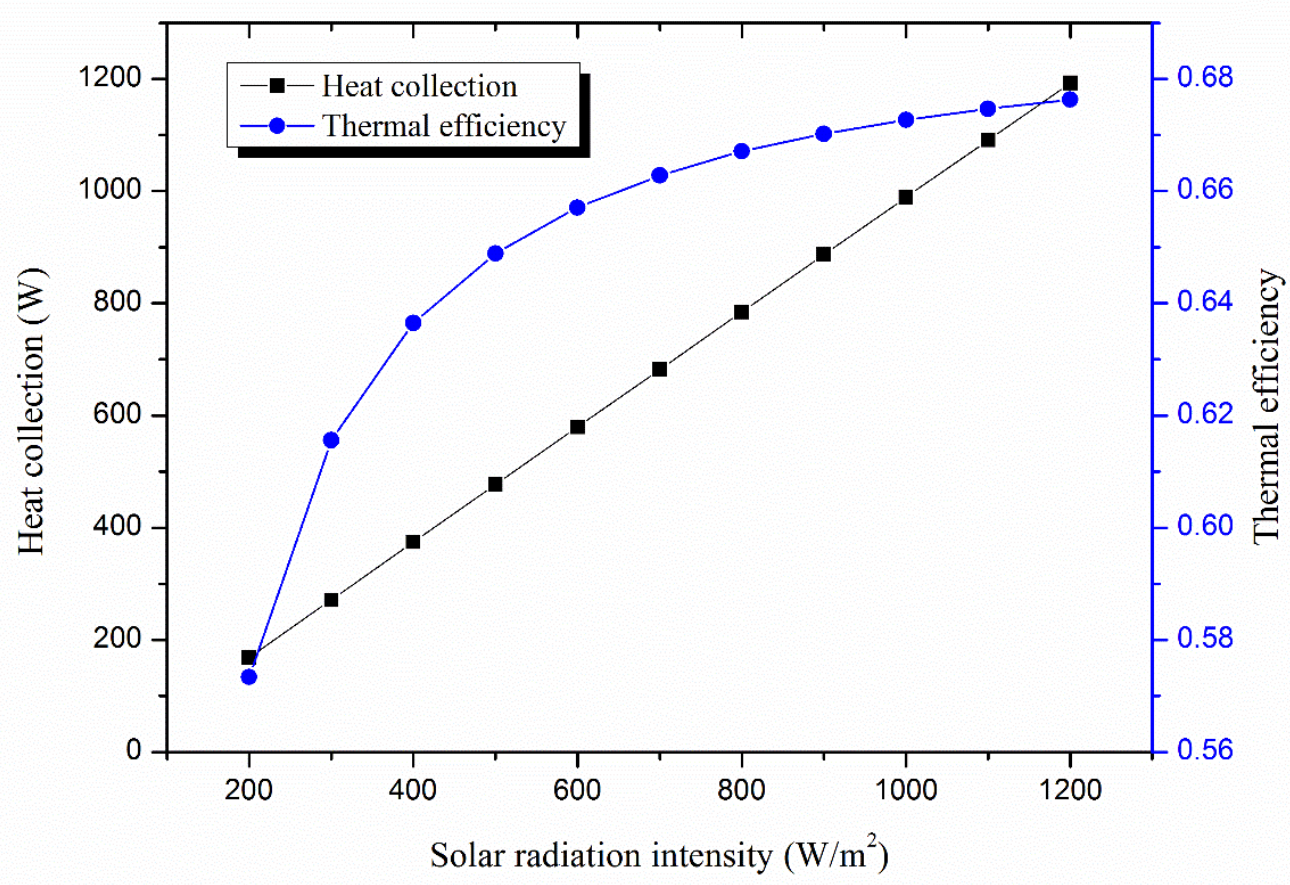

(a)

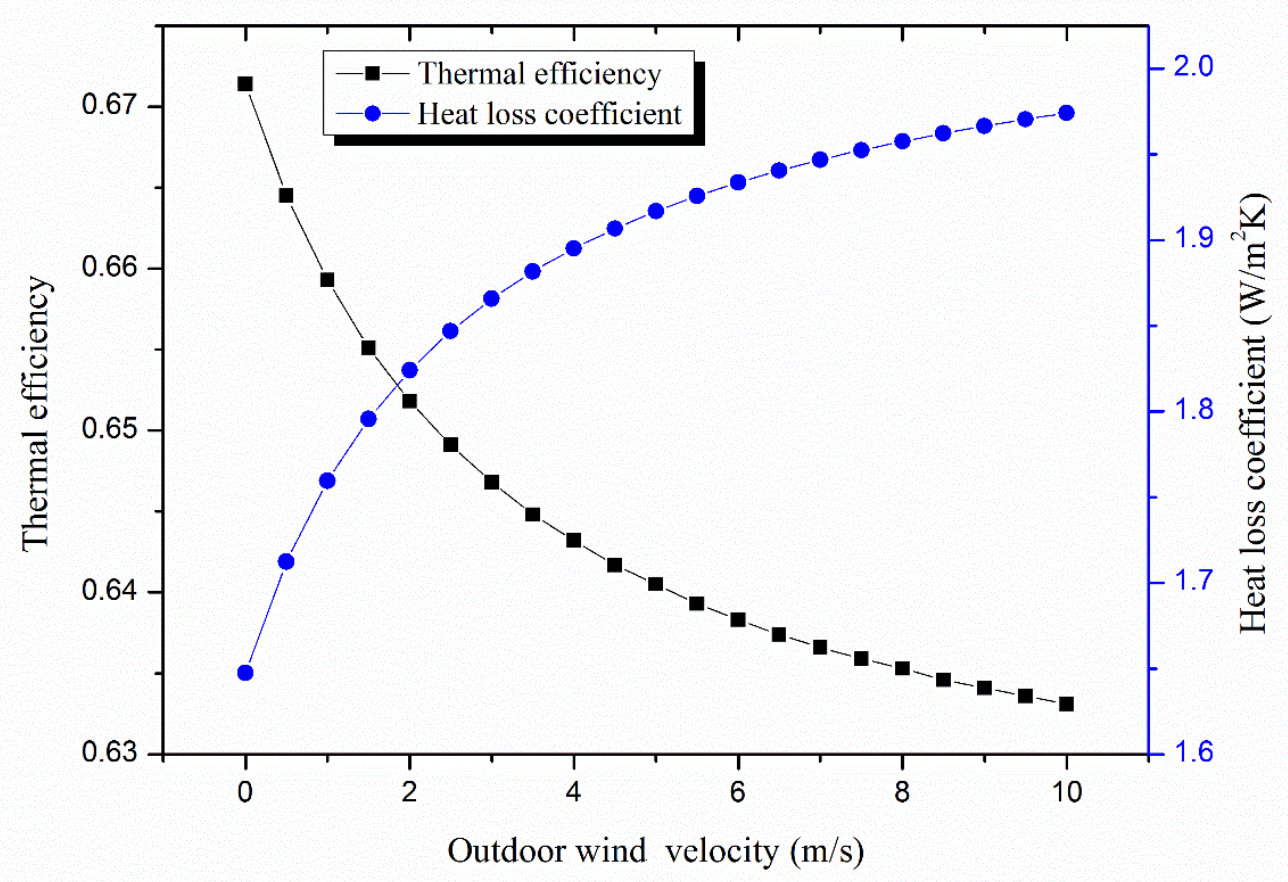

(b)

Fig. 12 Effect of (a) solar radiation intensity and (b) outdoor wind velocity on the thermal performance of the collector. 


\subsubsection{Air velocity in the collection}

The effective efficiency can be calculated by Gupta et al (2009), shown as follows.

$$
\eta_{e f}=\frac{q_{u}-W_{p} / C_{f}}{I_{c} A_{c}}=\eta-\frac{Q \Delta P / C_{f} / \eta_{p m}}{3600 I_{c} A_{c}}
$$

Where $\eta_{p m}$ is equal to 0.85 .

The increase of air velocity in the collector causes the time that air contacts with the absorber plate shorter, which is not sufficient for heat transfer. Temperature rise declines for $23.8 \mathrm{~K}$, as shown in Fig. 13(a). However, the increases of $v_{\text {slit }}$ and corresponding $h_{\text {slit }}$ are good for heat-transfer. In addition, with the decline of collector air temperature, the temperature difference between collector air and absorber plate gets larger, which results in the heat-exchange driving force strengthening. These two factors contribute to the increase of heat collection from $662.1 \mathrm{~W}$ to 819.5 W. However, the above all factors contribute to the reduction of varying rates of heat collection and temperature rise.

The variation of collector pressure drop is obtained from experimental data. When air velocity increases to $1.14 \mathrm{~m} / \mathrm{s}$, effective efficiency arrives at the peak, 67.83\%, as shown in Fig. 13(b). Therefore, the optimal air velocity in the collector is $1.14 \mathrm{~m} / \mathrm{s}$, which is equal to air flow rate of 288 $\mathrm{m}^{3} / \mathrm{h}$. It also can indicate that the air velocity has bigger influence on fan power than heat collection

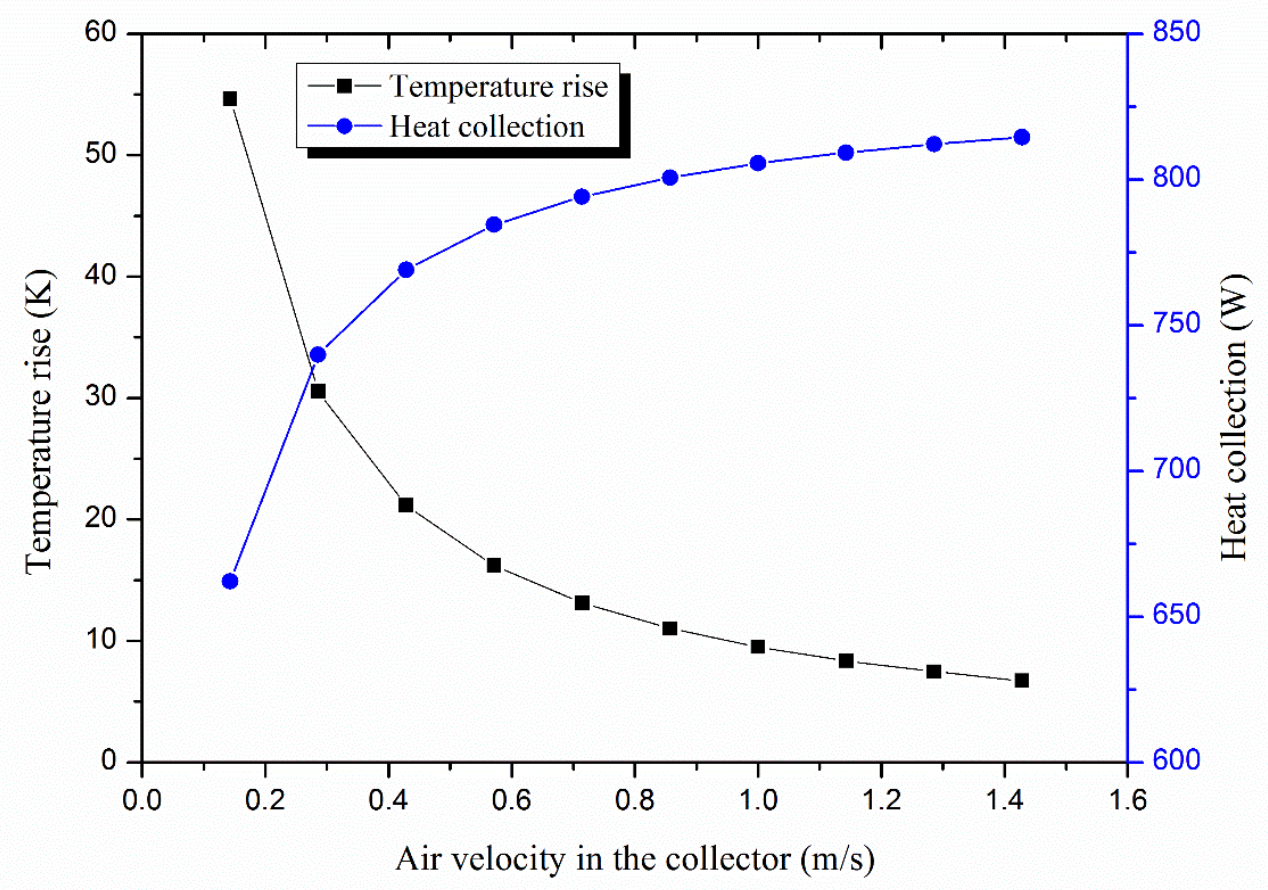

(a) 


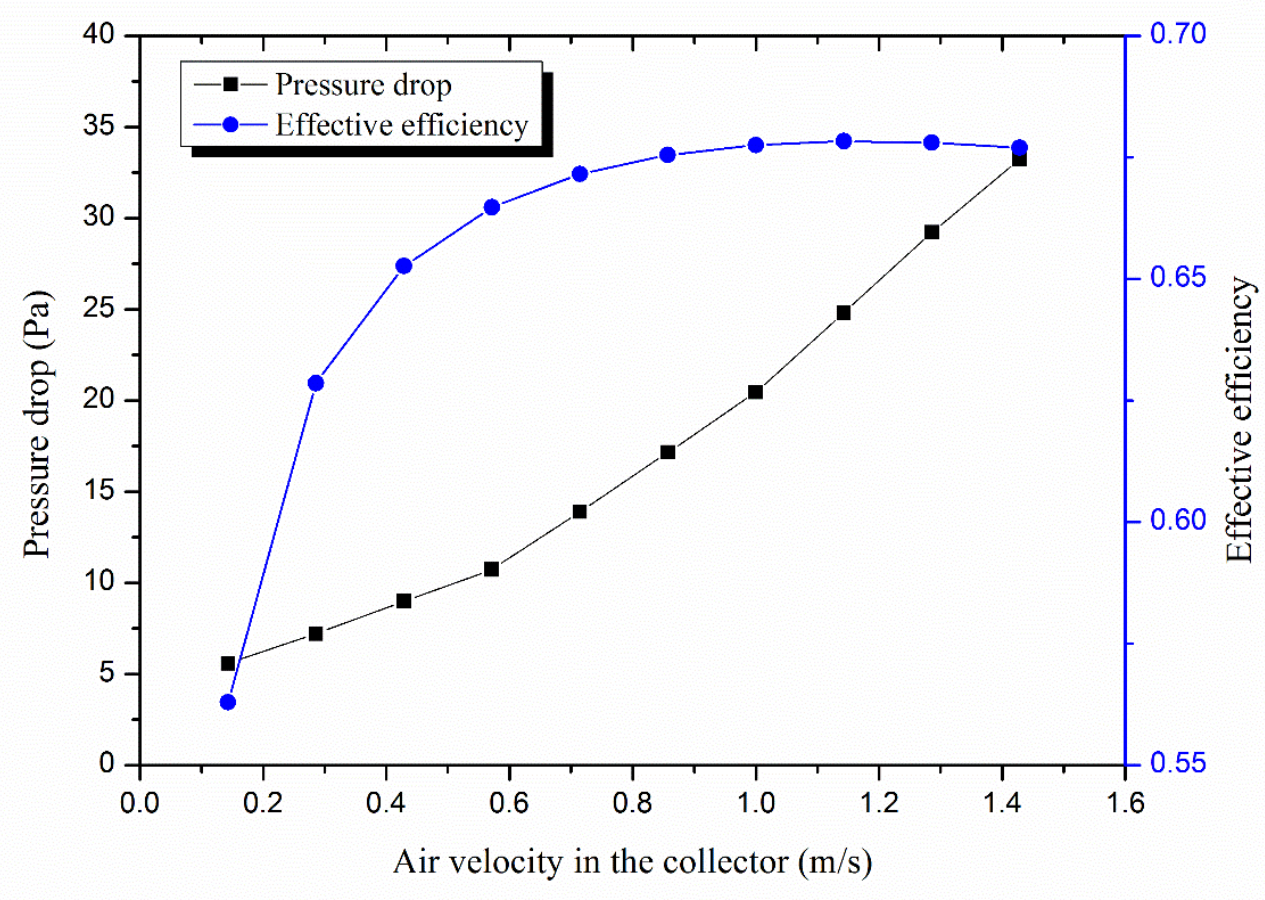

(b)

Fig. 13 (a) Temperature rise and heat collection (b) pressure drop and effective efficiency with air velocity in the collector.

\subsection{Contrastive analysis}

(1) $H=1.5 \mathrm{~m}, W=0.6 \mathrm{~m}, p=1 \%, D=0.001 \mathrm{~m}, I_{\mathrm{c}}=600 \mathrm{~W} / \mathrm{m}^{2}, T_{\mathrm{a}}=273 \mathrm{~K}, \mathrm{~V}_{\text {shiwai }}=0.4 \mathrm{~m} / \mathrm{s}, T_{\text {in }}=293 \mathrm{~K}$; (2) $H=1.9 \mathrm{~m}, W=0.7 \mathrm{~m}, p=10 \%, D=0.004 \mathrm{~m}, I_{\mathrm{c}}=800 \mathrm{~W} / \mathrm{m}^{2}, T_{\mathrm{a}}=275 \mathrm{~K}, \mathrm{~V}_{\text {shiwai }}=0.2 \mathrm{~m} / \mathrm{s}, T_{\text {in }}=288 \mathrm{~K}$.

(1) and (2) are respectively input parameters of simulation from Li et al. (2016)'s and Zheng et al. (2016)'s paper.

Fig. 14 illustrates the comparison between the present SAC and Li et al. (2016)'s and Zheng et al. (2016)'s SACs on heat collection, pressure drop and effective efficiency under the condition of same configuration and operation parameters. The results of Fig. 14(a) indicate that the heat collection of present SAC is higher than that of other two SACs. It is due to the enlargement of corrugated plate and the jet impingement caused by slit perforation. Based on the previous studies (Li et al., 2016), the local resistance coefficient of slit perforation is lower than that of circle holes. And compared with flat plate with slit-like perforation, the local resistance coefficient of slitperforated corrugated plate is smaller at same $p$ and $\operatorname{Re}_{\text {slit. }}$ It indicates that the pressure drop of SAC with slit-perforated corrugated plate is less than that of other two transpired SACs. The conclusion is consistent with the result of Fig. 14(b).

Therefore, thermo-hydraulic performance of present SAC is better than that of other two SACs, which can be shown in effective efficiency curve (Fig. 14(c)). It can be found that effective efficiency of SAC with slit-perforated corrugated plate is 1.6\%-2.7\% higher than that of SAC with flat plate with slit-like perforation ( $\mathrm{Li}$ et al., 2016) and 0.3\%-2.1\% higher than that of SAC with perforating corrugated plate (Zheng et al., 2016). Hence, the present solar collector is an efficient 
tool for different applications

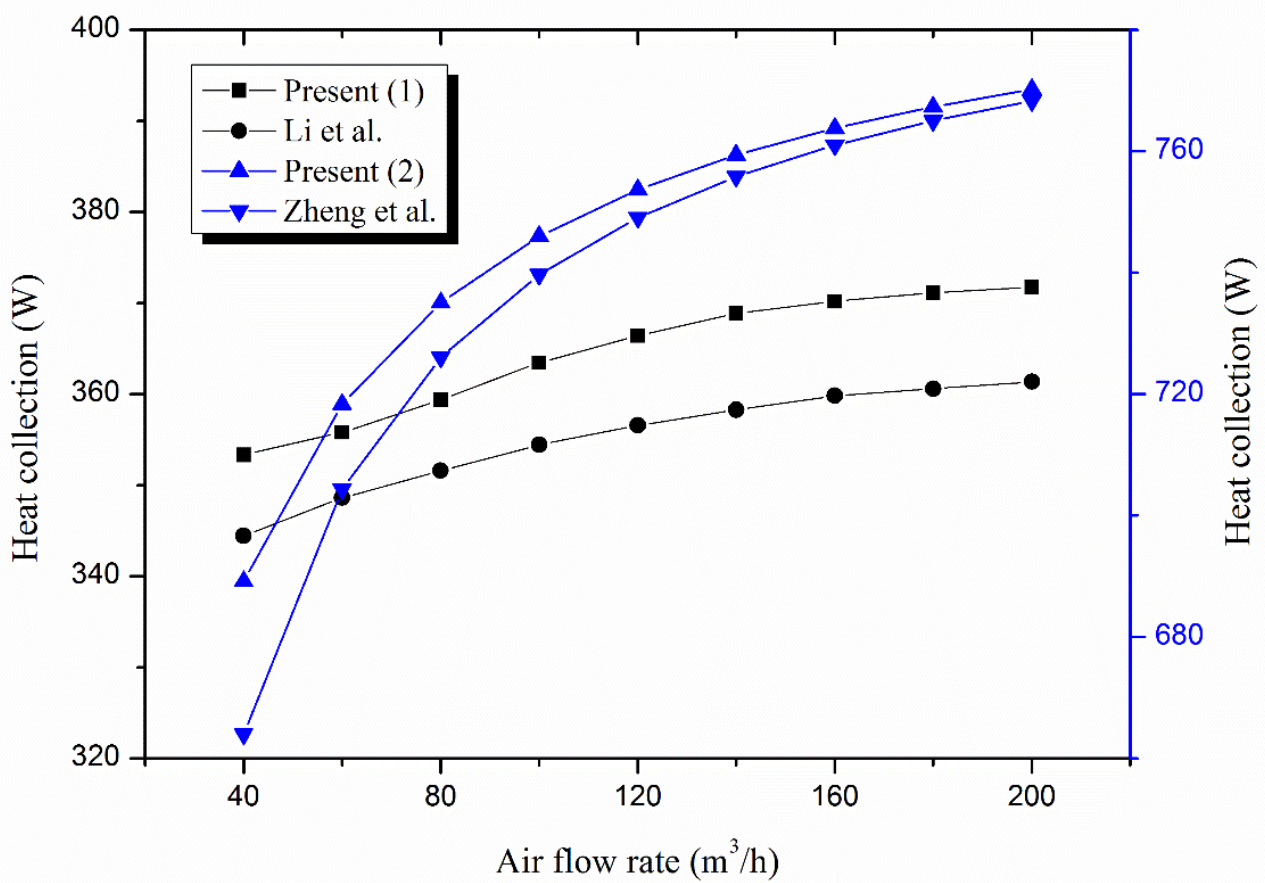

(a)

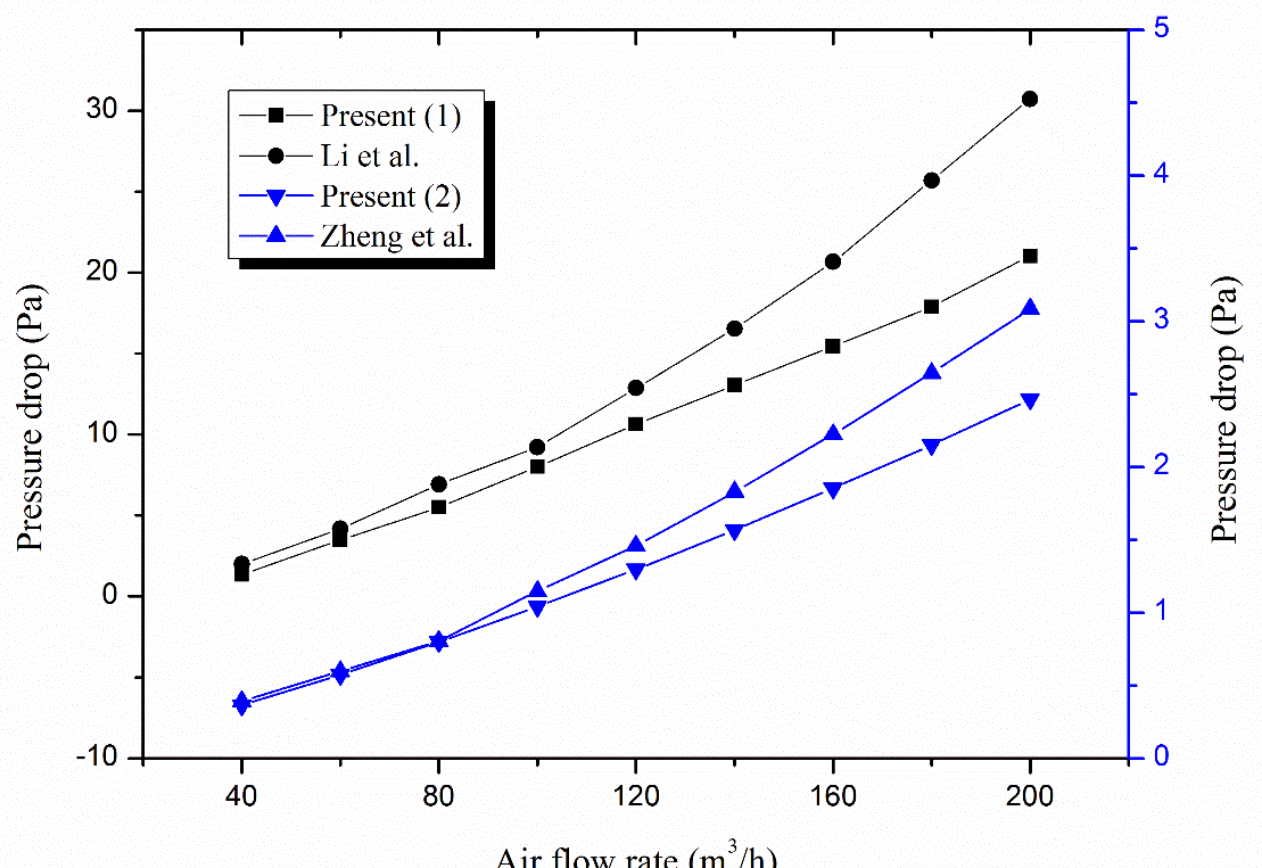

(b) 


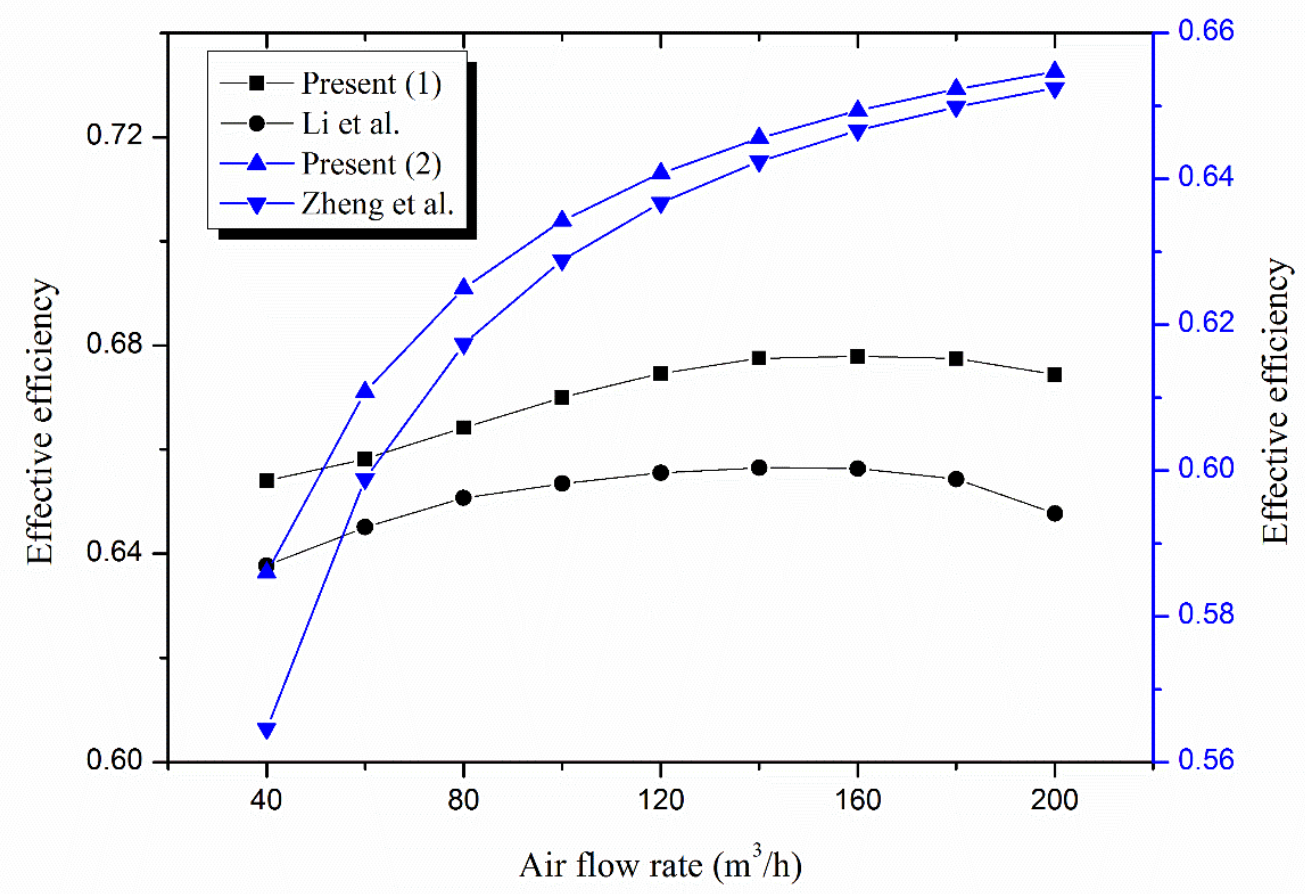

(c)

Fig. 14 Comparison with (1) Li et al. (2016)'s and (2) Zheng et al. (2016)'s SAC on (a) heat collection, (b) pressure drop, (c) effective efficiency.

\section{Case study}

In northern China, heating period begins 15th November and ends 15th March next year. The outdoor environment data (Zhang, 2005) of Tianjin is used to calculate the heat collection in the heating period. And the collector runs from 9:00 am to 15:00 pm every day except snowy and cloudy days. The result of calculation is shown in Tab. 5. The average thermal efficiency can arrive 51.9\%. If the efficiency of heating by boiler in rural area is $65 \%$ and the standard coal calorific value is 29.3 $\mathrm{MJ} / \mathrm{kg}$, it will save nearly $43.1 \mathrm{~kg}$ standard coal. It also can reduce $102.1 \mathrm{~kg}$ carbon dioxide emission according to Eq.(22). (Li et al., 2013). Hence, there is application potential for space heating in the cold region.

$$
m_{\left(\mathrm{co}_{2}\right)}=k m_{(\mathrm{coal})}
$$

Where $k$ is the transfer coefficient, 2.368.

Tab. 5 The calculation in the heating season

\begin{tabular}{cc}
\hline Item & The present SAC \\
\hline Heat collection $(\mathrm{MJ})$ & 820.7 \\
Hours for operating $(\mathrm{h})$ & 524 \\
Total solar radiation intensity $\left(\mathrm{MJ} / \mathrm{m}^{2}\right)$ & 1075.7 \\
Each heat collected $\left(\mathrm{MJ} / \mathrm{m}^{2}\right)$ & 558.3 \\
Average thermal efficiency & $51.9 \%$ \\
\hline
\end{tabular}




\section{Conclusion}

The objective of this paper is to investigate the performance of a glazed transpired solar collector with slit-perforated corrugated plate. A heat transfer model is established to investigate the thermal performance of the collector. The experiment system of collector was made and the local resistance coefficient of the collector is obtained. The relevant conclusions are as follows:

(1) The average bias between the simulated and experimental data is $4.8 \%$, which indicates that the thermal model is correct and reliable.

(2) The effect of structure parameters have been investigated. Using the Doe method, it can be found that the height of absorber plate has the largest effect on the thermal performance of collector, and the next one is the slit-perforation diameter.

(3) Due to the effect of heat-transfer driving force between collector and ambient air, the thermal efficiency of collector is higher for lower inlet air temperature, higher ambient air temperature and lower wind velocity. When air velocity in the collector increases to $1.14 \mathrm{~m} / \mathrm{s}$, effective efficiency reaches the peak, $67.83 \%$. The optimal air flow rate is 288 $\mathrm{m}^{3} / \mathrm{h}$.

(4) Compared with other transpired SACs, the present SAC with slit-perforated corrugated plate has better thermo-hydraulic performance than SAC with flat plate with slit-like perforation and SAC with perforating corrugated plate.

(5) In the case study, the application of the present solar air collector can produce $820 \mathrm{MJ}$, which can save $43.1 \mathrm{~kg}$ standard coal and reduce $102.1 \mathrm{~kg}$ carbon dioxide emission in the heating season.

\section{Acknowledgment}

This study is supported by the Opening Funds of State Key Laboratory of Building Safety and Built Environment (No. BSBE2016-09), Science and Technology Project of Urban-Rural Construction Commission of Tianjin Municipality (No. 2016-18) and the China Postdoctoral Science Foundation (No. 2016M600189).

\section{Nomenclature}

$\begin{array}{ll}A_{c} & \text { Aperture area }\left(\mathrm{m}^{2}\right) \\ b & \text { Slit width }(\mathrm{m}) \\ C & \text { Specific heat capacity of air }(\mathrm{J} / \mathrm{kg} \cdot \mathrm{K}) \\ D & \text { Slit-perforation equivalent diameter }(\mathrm{m}) \\ d & \text { Duct diameter }(\mathrm{m}) \\ d_{f 1} & \text { Thickness of Fluid } 1(\mathrm{~m}) \\ d_{f 2} & \text { Thickness of Fluid } 2(\mathrm{~m}) \\ f & \text { Friction factor } \\ \mathrm{Gz}_{s l i t} & \text { Graetz number } \\ h_{c v} & \text { Convection heat transfer coefficient }\left(\mathrm{W} / \mathrm{m}^{2} \mathrm{~K}\right)\end{array}$




\begin{tabular}{|c|c|}
\hline$h_{r}$ & Radiation heat transfer coefficient $\left(\mathrm{W} / \mathrm{m}^{2} \bullet \mathrm{K}\right)$ \\
\hline$h_{\text {slit }}$ & Convection heat transfer coefficient of slit perforation $\left(\mathrm{W} / \mathrm{m}^{2} \mathrm{~K}\right)$ \\
\hline$H$ & Collector height (m) \\
\hline$I_{c}$ & Solar radiation intensity $\left(\mathrm{W} / \mathrm{m}^{2}\right)$ \\
\hline$l$ & The perimeter of slit-perforation (m) \\
\hline$m$ & Mass $(\mathrm{kg})$ \\
\hline $\mathrm{Nu}$ & Nusselt number \\
\hline$p$ & Porosity \\
\hline$\Delta P$ & Pressure drop $(\mathrm{Pa})$ \\
\hline$P$ & The pitch of slit-perforation (m) \\
\hline$Q$ & Air flow rate $\left(\mathrm{m}^{3} / \mathrm{h}\right)$ \\
\hline$q_{c d}$ & Conductive heat $(\mathrm{W})$ \\
\hline$q_{r}$ & Radiation heat (W) \\
\hline$q_{c v}$ & Convection heat $(\mathrm{W})$ \\
\hline$q_{u}$ & Heat collection of the collector (W) \\
\hline $\operatorname{Re}$ & Reynolds number \\
\hline$R$ & Radius diameter $(\mathrm{m})$ \\
\hline$\delta_{p}$ & Thickness of absorber plate (m) \\
\hline$T$ & Temperature $(\mathrm{K})$ \\
\hline$T_{d b}$ & Dew point temperature $(\mathrm{K})$ \\
\hline$T_{\text {gnd }}$ & Ground temperature $(\mathrm{K})$ \\
\hline$T_{s k y}$ & Sky temperature $(\mathrm{K})$ \\
\hline$U$ & Heat loss coefficient $\left(\mathrm{W} /\left(\mathrm{m}^{2} \bullet \mathrm{K}\right)\right)$ \\
\hline$v_{\text {wind }}$ & Wind speed $(\mathrm{m} / \mathrm{s})$ \\
\hline$v_{\text {slit }}$ & Slit air velocity $(\mathrm{m} / \mathrm{s})$ \\
\hline$v_{f}$ & Surface suction velocity $(\mathrm{m} / \mathrm{s})$ \\
\hline$v_{d}$ & Duct air velocity $(\mathrm{m} / \mathrm{s})$ \\
\hline$v$ & Air velocity in the collector $(\mathrm{m} / \mathrm{s})$ \\
\hline$w$ & Uncertainty \\
\hline$W$ & Collector width (m) \\
\hline$a_{c}$ & Absorptivity of cover \\
\hline$\alpha_{p}$ & Absorptivity of absorber plate \\
\hline$\rho$ & Air density [kg/m3] \\
\hline$\tau_{c}$ & Transmissivity of cover \\
\hline$\lambda$ & Thermal conductivity $(\mathrm{W} / \mathrm{m} \bullet \mathrm{K})$ \\
\hline$\varepsilon_{\text {sky }}$ & Emissivity of air near the ground \\
\hline$\eta$ & Thermal efficiency \\
\hline$\eta_{e f}$ & Effective efficiency \\
\hline$\eta_{p m}$ & Fan-motor efficiency \\
\hline$\xi$ & Local drag coefficient \\
\hline$\theta$ & Angle between the absorber plate and the horizontal plane $\left(^{\circ}\right)$ \\
\hline $\mathrm{a}$ & Ambient air \\
\hline $\mathrm{b}$ & Backboard \\
\hline $\mathrm{c}$ & Cover \\
\hline
\end{tabular}




$\begin{array}{ll}\mathrm{f} 1 & \text { Air between cover and absorber plate } \\ \mathrm{f} 2 & \text { Air between absorber plate and backboard } \\ \mathrm{p} & \text { Absorber plate } \\ \text { slit } & \text { Slit-perforation } \\ \text { SAC } & \text { Solar air collector } \\ \text { UTC } & \text { Unglazed transpired solar air collector } \\ \text { GTC } & \text { Glazed transpired solar air collector }\end{array}$

\section{Reference}

Alam T., Saini R.P., Saini J.S., 2014. Use of turbulators for heat transfer augmentation in an air duct - a review. Renewable Energy, 62(3), 689-715.

Cho H.H. et al, 1997. Experimental mass (heat) transfer in and near a circular hole in a flat plate. International Journal of Heat \& Mass Transfer. 40(10), 2431-2443.

Decker G.W.E.V., Hollands K.G.T., Brunger A.P., 2001. Heat-exchange relations for unglazed transpired solar collectors with circular holes on a square or triangular pitch. Solar Energy, 71(1), 33-45.

El-Sebaii A.A., Aboul-Enein S., Ramadan M. R. I. et al., 2011. Investigation of thermal performance of-double pass-flat and v-corrugated plate solar air heaters. Energy, 36(2), 1076-1086.

Essalhi Hajar, Tadili Rachid, Bargach Mohammed, 2017. Conception of a Solar Air Collector for an Indirect Solar Dryer. Pear Drying Test. Energy Procedia. 141, 29-33.

Golneshan A.A., Nemati H., 2014. Exergy analysis of Unglazed Transpired Solar Collectors (UTCs). Solar Energy. 107(9), 272-277.

Gao L., Bai H., Mao S., 2014. Potential application of glazed transpired collectors to space heating in cold climates. Energy Conversion \& Management, 77(1), 690-699.

Gupta M.K., Kaushik S.C., 2009. Performance evaluation of solar air heater for various artificial roughness geometries based on energy, effective and exergy efficiencies. Renewable Energy, 34, 465-476.

Holman J.P., 2007. Experimental methods for engineers. New Delhi, India: Tata Mcgraw hill Publishing Company.

Kutscher C.F., 1994. Heat exchanger effectiveness and pressure drop for air flow through perforated plates, with and without crosswind. Heat Trans.-T ASME. 116, 391-399.

Karim M.A., Hawlader M.N.A., 2006. Performance investigation of flat plate, v-corrugated and finned air collectors. Energy, 31(4), 452-470.

Kumar R.A., Babu B.G., Mohanraj M., 2016. Thermodynamic performance of forced convection solar air heaters using pin-fin absorber plate packed with latent heat storage materials. Journal of Thermal Analysis \& Calorimetry, 126(3), 1657-1678.

Kumar R.A., Babu B.G., Mohanraj M., 2017. Experimental investigations on a forced convection solar air heater using packed bed absorber plates with phase change materials. International Journal of Green Energy, 14(15), 1238-1255.

Karim M.A., Perez E., Amin Z.M., 2014. Mathematical modelling of counter flow v-grove solar air collector. Renewable Energy, 67(4), 192-201.

Kasperski J., Nemś M., 2013. Investigation of thermo-hydraulic performance of concentrated solar 
air-heater with internal multiple-fin array. Applied Thermal Engineering, 58(1-2), 411-419.

Kumar A., Bhagoria J.L., Sarviya R.M., 2009. Heat transfer and friction correlations for artificially roughened solar air heater duct with discrete w-shaped ribs. Energy Conversion \& Management, 50(8), 2106-2117.

Leon M.A., Kumar S., 2007. Mathematical modeling and thermal performance analysis of unglazed transpired solar collectors. Solar Energy. 81(1), 62-75.

Li B., You S., Ye T. et al., 2014. Mathematical modeling and experimental verification of vacuum glazed transpired solar collector with slit-like perforations. Renewable Energy, 69(3), 43-49.

Li X., Li C., Li B., 2016. Net heat gain assessment on a glazed transpired solar air collector with slit-like perforations. Applied Thermal Engineering, 99, 1-10.

Li Q., Zheng C., Shirazi A., et al, 2017. Design and analysis of a medium-temperature, concentrated solar thermal collector for air-conditioning applications. Applied Energy. 190, 1159-1173.

Li B., You S., Zhang H. et al., 2013. Testing and analysis on solar assisted heat pump airconditioning system applied in rural residential buildings. Building Science, 29(2), 12-16.

Piao Y., 1992. Natural, forced and mixed convection in a vertical cross-corrugated channel. Mechanical Engineering.

Rajaseenivasan T., Srinivasan S., Srithar K., 2015. Comprehensive study on solar air heater with circular and v-type turbulators attached on absorber plate. Energy, 88, 863-873.

Singh S. et al., 2015. Thermo-hydraulic performance due to relative roughness pitch in v-down rib with gap in solar air heater duct - comparison with similar rib roughness geometries. Renewable \& Sustainable Energy Reviews.43, 1159-1166.

Sun D., 1987. The applicable range, defect and correction of equivalent diameter used hydraulic diameter. Journal of Engineering Thermophysics. 8, 357-364.

Su J., 2005. The design of experiment.Tsinghua University Press, Beijing.

McAdams W.H., 1954. Heat Transmission. McGraw-Hill New York. New York.

Zhang H., 2007. Solar Thermal Utilization Principle and Computer Simulation. Northwestern Polytechnical University Press, China.

Zhang Q.Y., 2005. Data set for the analysis of building thermal environment in China. Beijing: China Architecture and Building Press [in Chinese].

Zheng W., Li B., Zhang H. et al., 2016. Thermal characteristics of a glazed transpired solar collector with perforating corrugated plate in cold regions. Energy, 109, 781-790. 